\title{
1 Revealing RNA virus diversity and evolution in unicellular
}

\section{2 algae transcriptomes}

5 Justine Charon ${ }^{1}$, Shauna Murray ${ }^{2}$, Edward C. Holmes ${ }^{1 *}$

$8 \quad{ }^{1}$ Marie Bashir Institute for Infectious Diseases and Biosecurity, School of Life and

9 Environmental Sciences and School of Medical Sciences, The University of Sydney, Sydney

10 NSW 2006, Australia.

11 2University of Technology Sydney, School of Life Sciences, Sydney NSW 2007, Australia.

$14 *$ Corresponding author:

15 Prof. Edward C. Holmes,

16 Marie Bashir Institute for Infectious Diseases and Biosecurity, School of Life and

17 Environmental Sciences and School of Medical Sciences, The University of Sydney, Sydney

18 NSW 2006, Australia.

19 Email: edward.holmes@sydney.edu.au 


\section{Abstract}

21 Remarkably little is known about the diversity and evolution of RNA viruses in unicellular eukaryotes. We screened a total of 570 transcriptomes from the Marine Microbial Eukaryote Transcriptome Sequencing Project (MMETSP) project that encompasses a wide diversity of microbial eukaryotes, including most major photosynthetic lineages (i.e. the microalgae). From this, we identified 30 new and divergent RNA virus species, occupying a range of phylogenetic positions within the overall diversity of RNA viruses. Approximately one-third of the newly described viruses comprised single-stranded positive-sense RNA viruses from the order Lenarviricota associated with fungi, plants and protists, while another third were related to the order Ghabrivirales, including members of the protist and fungi-associated Totiviridae. Other viral species showed sequence similarity to positive-sense RNA viruses from the algae-associated Marnaviridae, the double-stranded RNA Partitiviridae, as well as a single negative-sense RNA virus related to the Qinviridae. Importantly, we were able to identify divergent RNA viruses from distant host taxa, revealing the ancestry of these viral families and greatly extending our knowledge of the RNA viromes of microalgal cultures. Both the limited number of viruses detected per sample and the low sequence identity to known RNA viruses imply that additional microalgal viruses exist that could not be detected at the current sequencing depth or were too divergent to be identified using sequence similarity. Together, these results highlight the need for further investigation of algalassociated RNA viruses as well as the development of new tools to identify RNA viruses that exhibit very high levels of sequence divergence. 


\section{Introduction}

Viruses likely infect most, if not all, cellular species. For example, metagenomic studies of marine environments have revealed an enormous abundance and diversity of both DNA and RNA viruses (up to $10^{8}$ viruses/ $\left.\mathrm{ml}\right)^{1}$ as well as their key role in biogeochemical processes ${ }^{2}$. diversity, including in host taxa that have only been poorly sampled to date ${ }^{3}$ Viruses of protists are a major exemplar of this untapped diversity.

Protists, defined as eukaryotic organisms that are not animal, plant, or fungi ${ }^{4}$, are

highly diverse and include the algae. Some protists play a critical role in ecosystems as primary producers as well as being involved in nutrient cycling. Next generation sequencing (NGS) of protists has shown that their diversity is far greater than previously thought, with species numbers likely exceeding one million, although only a tiny fraction have been described to date ${ }^{5}$. In addition, protists have already proven to be an important source of virus diversity, with the giant Mimiviridae from the Amoebozoa a notable case in point ${ }^{6}$. Despite this, protist viruses remain largely overlooked, especially those associated with the unicellular microalgae. This is particularly striking in the case of RNA viruses: although RNA viruses were first described in unicellular algae in $2003^{7}$, they still comprise only 73 species from a very small number of algal lineages (Figure $1 \mathrm{~A})^{8}$. eukaryotes $^{9,10}$. These have identified many thousands of virus sequences, with at least half

61 predicted to have RNA genomes ${ }^{11,12}$. Similarly, metagenomics is proving a valuable means to 62 mine viral diversity in uncultivable organisms ${ }^{13}$. However, because these studies have been 63 conducted with environmental samples they cannot identify the specific host taxon with certainty. 
A)

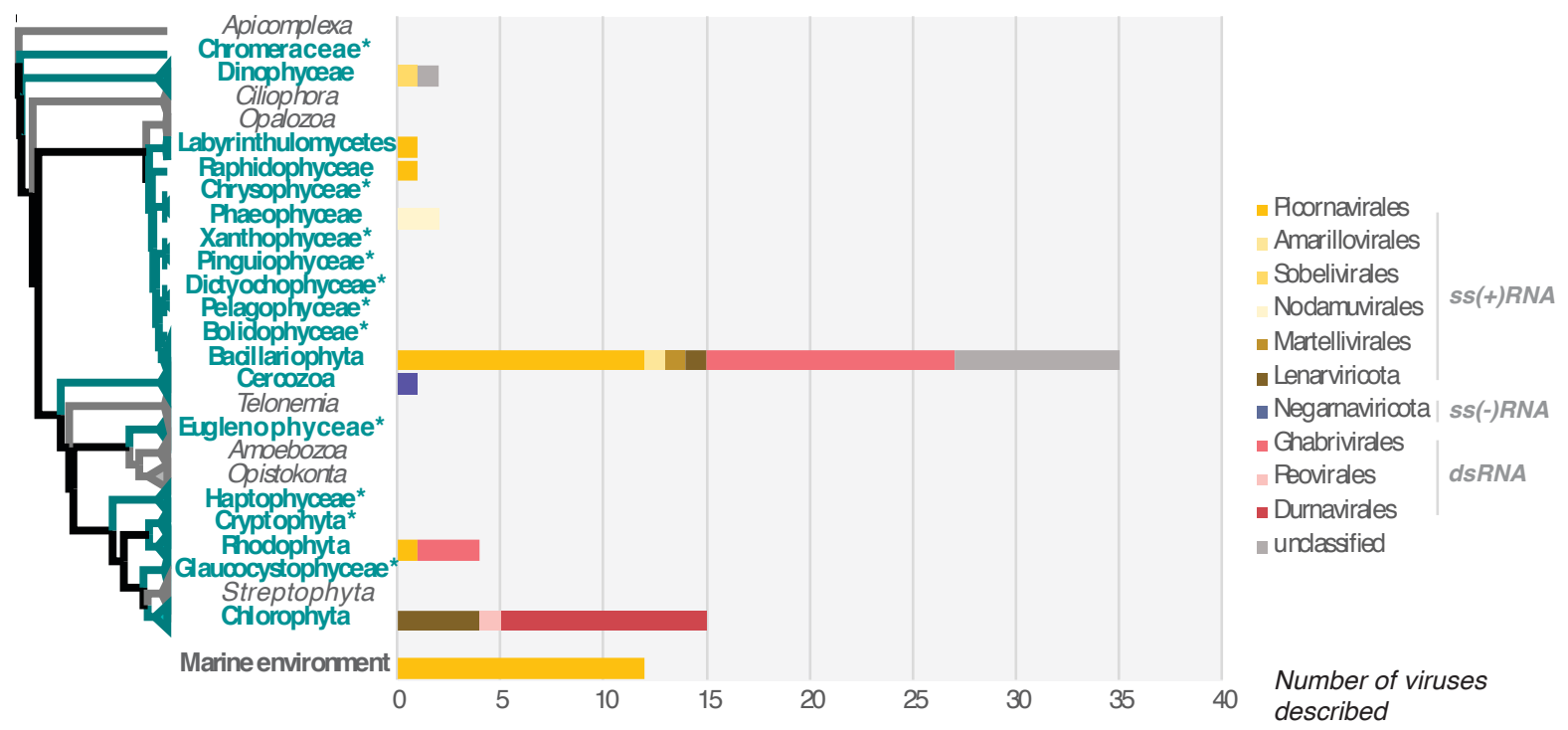

B)

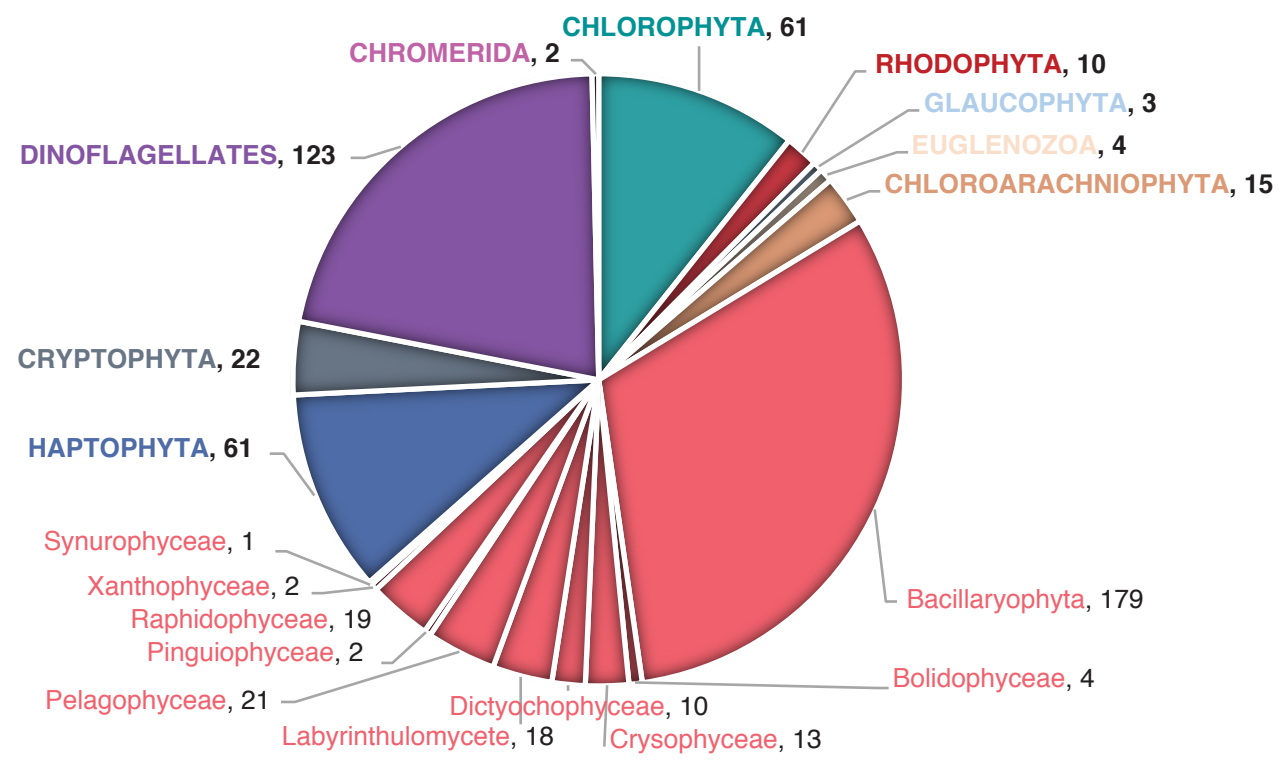

Figure 1. Currently reported RNA virus diversity in microalgae and the taxa studied investigated here are highlighted in bold green. *Microalgae lineages for which no RNA viruses have been reported to date. Right, number of total viruses formally or likely associated with microalgae reported at NCBI (https://www.ncbi.nlm.nih.gov/labs/virus/vssi/), VirusHostdb (https://www.genome.jp/virushostdb/) and the literature. Viruses are coloured based on their taxonomy and genome composition. (B) Representative taxa from major algal lineages used in this study and the total number of transcriptomes analysed for each lineage.

This illustrates the inference gap between broad scale metagenomic surveys that identify huge numbers of new viral sequences, creating a large but unassigned depiction of the virosphere, and those studies based on virus isolation and detailed particle characterization, 
including cell culture, that are conducted on a very limited of number of viruses and create a highly accurate, but very narrow, vision of the virosphere ${ }^{14}$. However, establishing strong links between viruses and their specific hosts provides a firmer understanding of virus ecology and evolution, as well as virus-host interactions. Hence, the NGS-based investigation of RNA virus diversity from individual host species serves as a good compromise to fill the gap between large-scale virus detection through metagenomics and the detailed assignment of hosts through virus isolation and cell culture.

To better understand diversity of RNA viruses associated with microalgae, we performed viral metatranscriptomic analyses of data obtained from the Marine Microbial Eukaryote Transcriptome Sequencing Project (MMETSP) ${ }^{15}$. With 210 unique genera covering most unicellular algal-comprising lineages, the MMETSP constitutes the largest collection of transcriptome data collected from microbial eukaryote cultures, including axenic ones, and hence depicts a large component of eukaryotic diversity ${ }^{15}$ (Figure 1). Accordingly, we used both sequence and structural-based approaches to screen 570 transcriptomes from 19 major microalgae-containing lineages for the most conserved "hallmark" protein of RNA viruses - the RNA-dependent RNA polymerase (RdRp). To the best of our knowledge, this is the broadest exploration of RNA viruses conducted at the single host species level in microbial eukaryotes and the first attempt to identify RNA viruses in most of the microalgal lineages investigated here (Figure 1).

\section{Methods}

\subsection{MMETSP contig retrieval}

In total, 570 MMETSP accessions, corresponding to the microalgal-containing lineages, were included in this study. Contig data sets corresponding to each accession were retrieved from a Trinity re-assembly performed on the RNA-Seq data sets from MMETSP and available at 
https://doi.org/10.5281/zenodo. $740440^{16}$. A description of all the transcriptome accessions and samples analysed here is available in Table S1.

\subsection{ORF annotation}

To optimize our computational analysis of the 570 contig data sets, we focused on those predicted to encode ORFs with a minimum length of 200 amino acids (assuming that shorter contigs would be too short to be included in a robust phylogenetic analyses). Accordingly, ORFs $>200$ amino acids in length were predicted using the GetORF tool from the EMBOSS package (v6.6.0). ORFs were predicted using the standard genetic code (with alternative initiation codons) as alternative genetic codes are not used in the microalgae analysed here ${ }^{17}$. The option -find 0 (translation of regions between STOP codons) was used to enable the detection of partial genomes, in which START codons could be missing due to partial virus genome recovery.

\subsection{RNA virus sequence detection using sequence similarity}

All predicted ORFs were compared to the entire non-redundant protein database (nr) (release April 2020) using DIAMOND BLASTp (v0.9.32) ${ }^{18}$ with the following options: --max-targetseqs 1 (top hit with best score retained) and an e-value cut-off of 1e-03. Additional sequence comparisons with identical BLASTp parameters were performed using either the newlydetected RdRp sequences or the RdRps from a previous large-scale analysis ${ }^{12}$ (available at ftp://ftp.ncbi.nih.gov/pub/wolf/_suppl/yangshan/rdrp.ya.fa).

To limit false-negative detection due to a bias in ORF prediction (in particular, partial genomes may not be detected due to their short length), all the contig nucleotide sequences were submitted to a RdRp protein database using DIAMOND BLASTx (v0.9.32, more sensitive option and 1e-03 e-value cut-off) ${ }^{18}$ to identify any additional RNA viruses. Top hits were retained and re-submitted against the entire nr protein database (April 2020 release) to 
remove false-positive hits (queries with a greater match to non-viral hits). All sequences retained from both the BLASTp and RdRp BLASTx analysis were manually checked to remove non-RNA virus sequences based on their taxonomy (predicted using the TaxonKit tool from NCBI; https://github.com/shenwei356/taxonkit).

All RNA virus-like sequences detected were functionally annotated using InterProscan (v5.39-77.0, default parameters) and non-RdRp sequences were filtered out. One sequence, sharing homology with the QDH87844.1 hypothetical protein H3RhizoLitter144407_000001, partial [Mitovirus sp.], was observed in 86 of the 570 data sets, including multiple species from multiple sampling locations. Considering the prevalence of this hit and the $100 \%$ identity between samples, we assumed this originates from environmental or sequencing-associated contamination. In addition, a small number of RNA virus-like sequences were identified based on their similarity to the $R d R p$ from bovine viral diarrhea viruses 1 and 2 and considered biological product contaminants ${ }^{19}$. These were also discarded.

\subsection{RNA virus sequence detection using protein profiles and 3D structures}

In an attempt to detect more divergent viral RdRps we compared all the "orphan" ORFs (i.e. ORFs without any BLASTp hits at the 1e-03 e-value cut-off) against the viral RdRp-related profiles from the PFAM ${ }^{20}$ and PROSITE databases (Table S2) using the HMMer3 program ${ }^{21}$ (v3.3, default parameters, e-value $<1 \mathrm{e}-05$ ). An additional attempt to annotate orphan translated-ORFs was performed on the remaining sequences using the InterProscan software package from EMBL-EBI (v5.39-77.0, default parameters) (https://github.com/ebi-pfteam/interproscan).

The RdRp-like candidates identified in both the HMMer3 and InterProscan analysis were submitted to the Protein Homology/analogY Recognition Engine v 2.0 (Phyre2) web portal $^{22}$ to confirm the presence of a RdRp signature (Table S3). Non-viral proteins (i.e. non- 
151

viral Phyre2 hit $>90 \%$ confidence) were discarded, as were sequences with low HMM (evalue $>1$ e-03) and Phyre2 scores (confidence level $>90 \%$ ). Sequences that matched either the HMM RdRp ( $>1$ e-05) and/or Phyre2 RdRp ( $>90 \%$ confidence) were retained for further characterization as potential RNA viruses. In total, $80 \mathrm{RdRp}$-like candidates were qualityassessed by coverage analysis and manual checked for the presence of the standard A, B and C catalytic viral RdRp sequence motifs ${ }^{23}$ using Geneious (v11.1.4) ${ }^{24}$. Only those displaying related RdRp-like motifs were retained as potential RdRp protein candidates (Table S3).

\subsection{Contig manual extension and genome annotation}

Full-length nucleotide sequences encoding the protein retained from the sequence-based and structure-based detection approaches were retrieved and used as references for mapping SRA reads corresponding to each sample (BioProject PRJNA231566) using the SRA extension package of Bowtie2 (v2.3.5.1-sra) ${ }^{25}$. Read coverages of each contig were checked using Geneious (v11.1.4) and, when needed, extremities were manually extended and contigs resubmitted to read mapping, until no overhanging extremities were observed.

The relative abundance of each putative viral sequence was reported as the number of reads per million: that is, the number of reads mapping to the contig divided by the total number of reads of the corresponding SRA library multiplied by one million. Poorlyrepresented viral sequences were considered as potential cross-library contaminants derived from index-hopping and discarded when they accounted for less than $0.1 \%$ of the highest abundance of the same sequence in another library ${ }^{26}$.

Genomic organizations were constructed using Geneious (v11.1.4). ORFs were predicted using the standard genetic code or, when suitable, using alternative mitochondrial or plastid-associated genetic codes. Tentative virus names were taken from Greek mythology. 


\subsection{Host $r b c L$ gene abundance estimation}

175 To estimate levels of virus abundance in comparison to those from their putative hosts, the abundance of the host Ribulose bisphosphate carboxylase large chain $(r b c L)$ gene was assessed using the Bowtie2 SRA package (v2.3.5.1-sra) and mapped to SRA reads from the $r b c L$ gene of each corresponding species (whenever available) ${ }^{25}$. The SRA and $r b c L$ gene accessions used are reported in Table S4.

\subsection{Secondary host profiling}

According to the MMETSP sample requirements, all cultures were subjected to SSU rRNA sequencing to ensure they were mono-strain and not contaminated with additional microbial eukaryotes. Nevertheless, the presence of other microbial contaminants was possible. As we expect most of the potential Archaea and Bacteria contaminants will not have an available genome sequence, their profiling in the samples was performed by analysing the closest homologs of each contig using both BLASTn (BLAST+ package, v2.9.0) and BLASTp (DIAMOND, v2.0.4) against the nt and nr databases, respectively. Contigs were grouped at the kingdom level based on the taxonomic affiliation of their closest homologs in the databases, with the abundance of each kingdom defined as the sum of each contig abundance value (transcripts per million) ${ }^{16}$.

\subsection{Phylogenetic analysis}

For each virus phylum and order, the RefSeq and most closely related RdRp sequences were retrieved from GenBank and aligned with newly identified RdRp sequences using the L-INSI algorithm in the MAFFT program (v7.402) ${ }^{27}$. Resulting sequence alignments were trimmed using TrimAl to remove ambiguously aligned regions with different levels of stringency, optimized for each alignment (v1.4.1, "automated1" mode). Maximum likelihood phylogenies based on amino acid alignments were inferred using IQ-TREE (v2.0-rc1) ${ }^{28}$, with 
ModelFinder used to find the best-fit substitution model in each case (see figure legends) ${ }^{29}$

200 (1000 replicates) used to assign support to individual nodes ${ }^{30}$. All phylogenies were

201 visualized, and mid-point rooted (for clarity only) using the Figtree software (v1.4.4).

\subsection{Detection of endogenous viral elements}

To determine whether any of the newly detected viral sequences were endogenous viral elements (EVEs) rather than true exogenous viruses, the nucleotide sequences of viral candidates were used as a query for BLASTn (online version, default algorithm parameters) against corresponding host genome sequence, whenever available.

\section{Results}

\subsection{Overall virus diversity}

209 Our analysis of the 570 MMETSP transcriptomes obtained from 247 total microalgal species

210 spread over 10 major groups of algae (Table 1B) identified 30 new RNA viral species. These newly identified viruses largely represented the single-stranded positive-sense RNA

212 (ssRNA+) virus phylum Lenarviricota and the order Picornavirales (Figure 2A and B), as

213 well as the double-stranded (dsRNA) RNA virus orders Durnavirales and Ghabrivirales

214 (Figure 2C and D). A single negative-sense RNA (ss-RNA) virus was also identified in

215 Pseudo-nitzchia heimii that fell within the Qinviridae (order Muvirales). 
A)

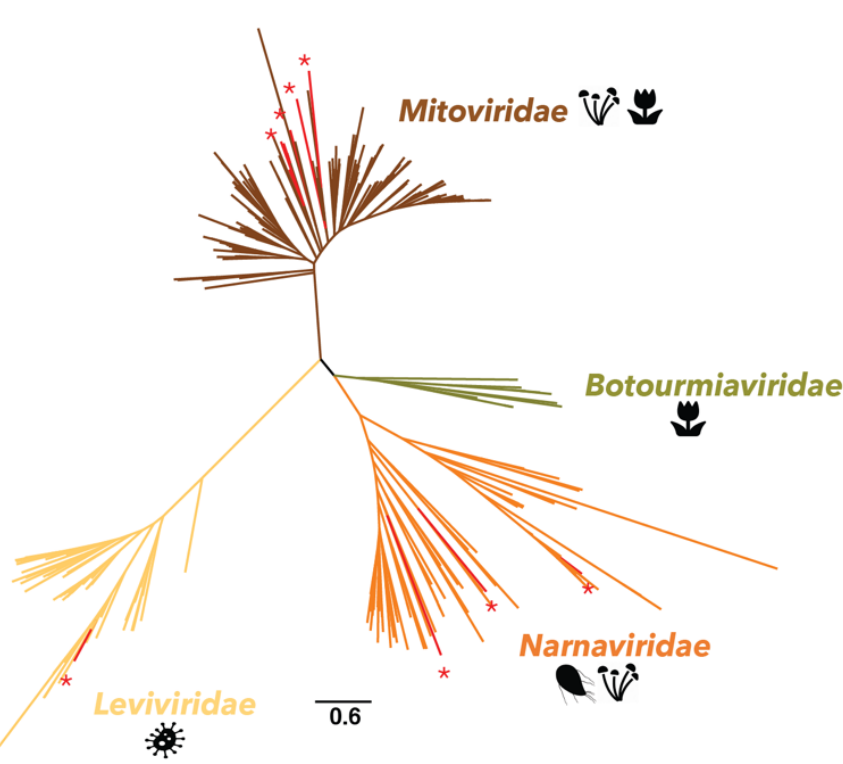

C)
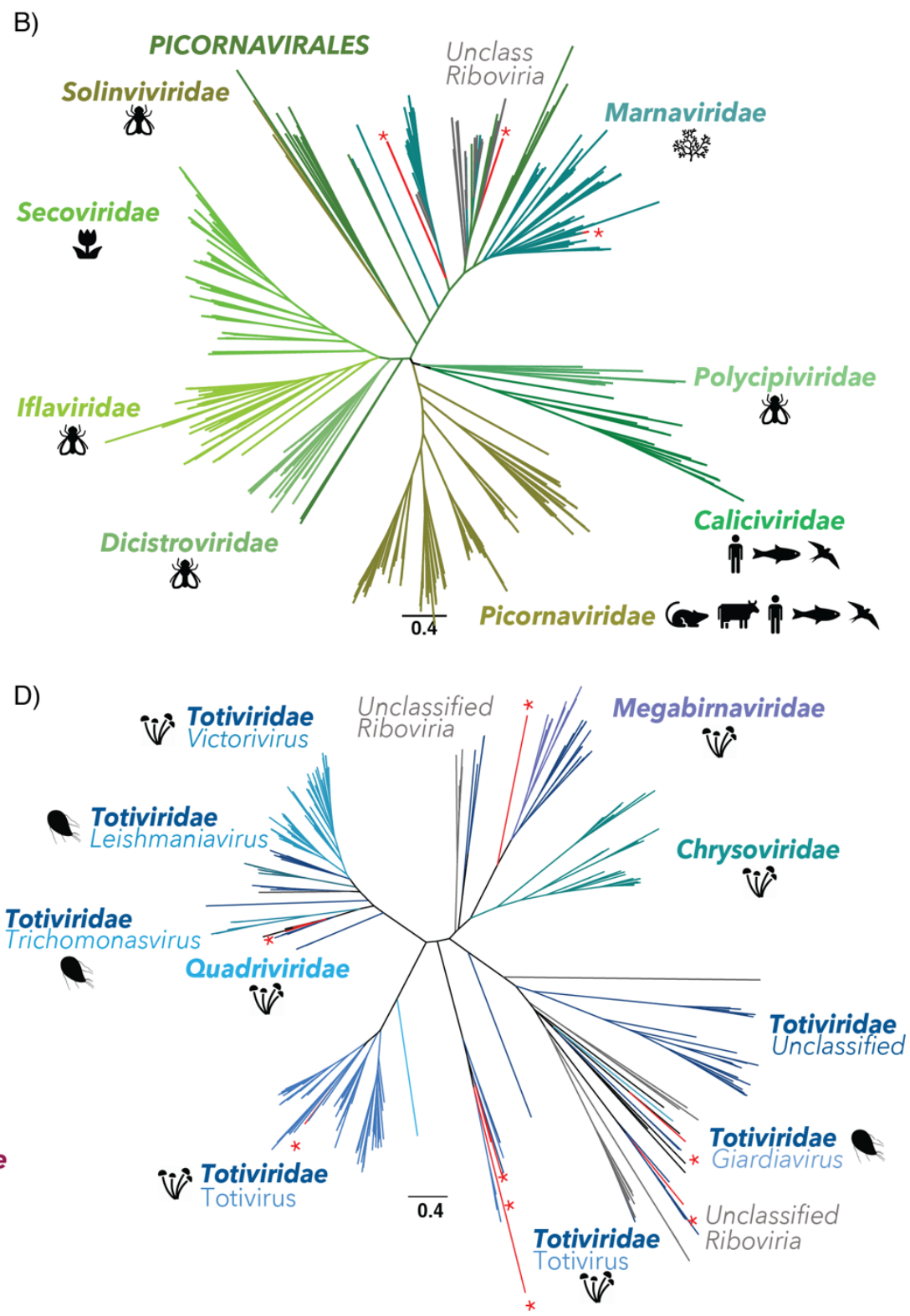
Figure 2. Newly described RNA virus sequences within the diversity of RNA viruses using RdRp phylogenies. Newly described sequences are indicated in red with "*" symbols. Phylogenies of: (A) the phylum Lenarnaviricota (ssRNA+); (B) the order Picornavirales (ssRNA+); (C) the order Durnavirales (dsRNA); (D) the order Ghabrivirales (dsRNA). For each viral family, the host range was retrieved from VirusHostdb and the ICTV report ${ }^{31,32}$. 
Table 1. List of new RNA viruses discovered in this study. Read abundances are indicated as the number of reads per million. Likely hosts correspond to eukaryotic lineages detected at levels using BLASTn/BLASTp analysis and phylogenies.

\begin{tabular}{|c|c|c|c|c|c|c|c|c|c|}
\hline Virus name & $\begin{array}{l}\text { MMETSP sample } \\
\text { (Phylum/class) }\end{array}$ & $\begin{array}{l}\text { Genome } \\
\text { status }\end{array}$ & $\begin{array}{l}\text { Reads/ } \\
\text { million }\end{array}$ & $\begin{array}{c}\text { BLASTp best hits } \\
\text { (GenBank acc./Organism) }\end{array}$ & $\%$ ID & E-value & $\begin{array}{l}\text { Likely host(s) } \\
\text { (BLAST) }\end{array}$ & $\begin{array}{c}\text { Likely host(s) } \\
\text { (Phylogenies) }\end{array}$ & Proposed host \\
\hline $\begin{array}{l}\text { Amphitrite narna- } \\
\text { like virus }\end{array}$ & $\begin{array}{l}\text { MMETSP1061 } \\
\text { P.pungens } \\
\text { (Bacillariophyta) }\end{array}$ & $\begin{array}{l}\text { Full- } \\
\text { length }\end{array}$ & 48 & $\begin{array}{c}\text { QIR30281.1 RdRp } \\
\text { [Plasmopara viticola associated } \\
\text { narnavirus 2] }\end{array}$ & 41 & $5 \mathrm{E}-144$ & Bacillariophyta & Fungi/Protist & Bacillariophyta \\
\hline $\begin{array}{l}\text { Poseidon narna- } \\
\text { like virus }\end{array}$ & $\begin{array}{l}\text { MMETSP0418 } \\
\text { A. radiata } \\
\text { (Bacillariophyta) }\end{array}$ & Partial & 8 & $\begin{array}{c}\text { QDH89392.1 RdRp, partial } \\
\text { [Mitovirus sp.] }\end{array}$ & 34 & $4 \mathrm{E}-17$ & Bacillariophyta & $\begin{array}{l}\text { Marine } \\
\text { arthropod }\end{array}$ & Bacillariophyta \\
\hline $\begin{array}{l}\text { Halia narna-like } \\
\text { virus }\end{array}$ & $\begin{array}{l}\text { MMETSP0418 } \\
\text { A. radiata } \\
\text { (Bacillariophyta) }\end{array}$ & $\begin{array}{l}\text { Full- } \\
\text { length }\end{array}$ & 108 & $\begin{array}{l}\text { QBC65281.1 RdRp, partial } \\
\text { [Rhizopus microsporus 23S } \\
\text { narnavirus] }\end{array}$ & 32 & $4 \mathrm{E}-17$ & Bacillariophyta & Protist & Bacillariophyta \\
\hline $\begin{array}{l}\text { Triton levi-like } \\
\text { virus }\end{array}$ & $\begin{array}{l}\text { MMETSP1471 } \\
\text { P. provasolii } \\
\text { (Chlorophyta) }\end{array}$ & Partial & 64 & $\begin{array}{c}\text { APG76993.1 hypothetical } \\
\text { protein [Beihai levi-like virus } \\
\text { 20] }\end{array}$ & 46 & $3 \mathrm{E}-65$ & $\begin{array}{l}\text { Chlorophyta; } \\
\text { Bacteria }\end{array}$ & Bacteria & Bacteria \\
\hline $\begin{array}{l}\text { Aiolos mito-like } \\
\text { virus }\end{array}$ & $\begin{array}{l}\text { MMETSP0286 } \\
\text { P. polylepis } \\
\text { (Haptophyta) }\end{array}$ & $\begin{array}{l}\text { Full- } \\
\text { length }\end{array}$ & 54 & $\begin{array}{c}\text { YP_009272901.1 RdRp } \\
\text { [Fusarium poae mitovirus 4] }\end{array}$ & 35 & $3 \mathrm{E}-38$ & Haptophyta & Sea sponge & Haptophyta \\
\hline $\begin{array}{l}\text { Asopus mito-like } \\
\text { virus }\end{array}$ & $\begin{array}{l}\text { MMETSP0164 } \\
\text { C. braarudii } \\
\text { (Haptophyta) }\end{array}$ & Partial & 12 & $\begin{array}{c}\text { QDM55307.1 RdRp } \\
\text { [Geopora sumneriana mitovirus } \\
\text { 1] }\end{array}$ & 34 & $2 \mathrm{E}-35$ & Haptophyta & Sea sponge & Haptophyta \\
\hline $\begin{array}{l}\text { Athena mito-like } \\
\text { virus }\end{array}$ & $\begin{array}{l}\text { MMETSP0719 } \\
\text { C. curvisetus } \\
\text { (Bacillariophyta) }\end{array}$ & Partial & 54 & $\begin{array}{l}\text { ASM94070.1 putative RdRp, } \\
\text { partial [Barns Ness breadcrumb } \\
\text { sponge narna-like virus 5] }\end{array}$ & 65 & $6 \mathrm{E}-72$ & $\begin{array}{l}\text { Bacillariophyta; } \\
\text { Bacteria }\end{array}$ & Sea sponge & Bacillariophyta \\
\hline $\begin{array}{l}\text { Daimones mito-like } \\
\text { virus }\end{array}$ & MMETSP0286 & $\begin{array}{l}\text { Full- } \\
\text { length }\end{array}$ & 104 & $\begin{array}{c}\text { YP_009552787.1 RNA-directed } \\
\text { RNA polymerase }\end{array}$ & 26 & $4 \mathrm{E}-16$ & Haptophyta & $\begin{array}{l}\text { Freshwater } \\
\text { arthropods }\end{array}$ & Haptophyta \\
\hline
\end{tabular}




\begin{tabular}{|c|c|c|c|c|c|c|c|c|c|}
\hline & $\begin{array}{l}\text { P.polylepis } \\
\text { (Haptophyta) }\end{array}$ & & & $\begin{array}{l}\text { [Rhizophagus sp. RF1 } \\
\text { mitovirus] }\end{array}$ & & & & & \\
\hline $\begin{array}{l}\text { Despoena mito-like } \\
\text { virus }\end{array}$ & $\begin{array}{l}\text { MMETSP0167 } \\
\text { R. maculata } \\
\text { (Rhodophyta) }\end{array}$ & $\begin{array}{l}\text { Full- } \\
\text { length }\end{array}$ & 115 & $\begin{array}{c}\text { ALM62241.1 RdRp } \\
\text { [Soybean leaf-associated } \\
\text { mitovirus 1] }\end{array}$ & 34 & $6 \mathrm{E}-32$ & $\begin{array}{l}\text { Rhodophyta; } \\
\text { Bacteria }\end{array}$ & $\begin{array}{l}\text { Freshwater } \\
\text { arthropods }\end{array}$ & Rhodophyta \\
\hline $\begin{array}{l}\text { Proteus mito-like } \\
\text { virus }\end{array}$ & $\begin{array}{l}\text { MMETSP1081 } \\
\text { P. amylifera } \\
\text { (Chlorophyta) }\end{array}$ & $\begin{array}{l}\text { Full- } \\
\text { length }\end{array}$ & 388 & $\begin{array}{c}\text { ALM62242.1 RdRp } \\
\text { [Soybean leaf-associated } \\
\text { mitovirus 2] }\end{array}$ & 32 & $7 \mathrm{E}-46$ & Chlorophyta & Fungi/Protist & Chlorophyta \\
\hline \multirow{2}{*}{$\begin{array}{l}\text { Telchines mito-like } \\
\text { virus }\end{array}$} & $\begin{array}{l}\text { MMETSP0725 } \\
\text { Amphiprora } \\
\text { (Bacillariophyta) }\end{array}$ & Partial & 15 & \multirow{2}{*}{$\begin{array}{l}\text { QDA33961.1 RdRp } \\
\text { [Mitovirus 1 BEG47] }\end{array}$} & \multirow{2}{*}{25} & \multirow{2}{*}{$5 \mathrm{E}-21$} & \multirow{2}{*}{ Bacillariophyta } & \multirow{2}{*}{ Algae } & \multirow{2}{*}{ Bacillariophyta } \\
\hline & $\begin{array}{l}\text { MMETSP0724 } \\
\text { Amphiprora } \\
\text { (Bacillariophyta) }\end{array}$ & Partial & 26 & & & & & & \\
\hline Susy yue-like virus & $\begin{array}{c}\text { MMETSP1423 } \\
P . \text { heimii } \\
\text { (Bacillariophyta) }\end{array}$ & Partial & 5 & $\begin{array}{l}\text { QDH86724.1 RdRp, partial } \\
\text { [Qinviridae sp.] }\end{array}$ & 42 & $1 \mathrm{E}-21$ & Bacillariophyta & $\begin{array}{l}\text { Soil samples/ } \\
\text { Marine } \\
\text { arthropod }\end{array}$ & Bacillariophyta \\
\hline $\begin{array}{l}\text { Aethusa amalga- } \\
\text { like virus }\end{array}$ & $\begin{array}{l}\text { MMETSP0011 } \\
\text { R. marinus } \\
\text { (Rhodophyta) }\end{array}$ & Partial & 83 & $\begin{array}{c}\text { ANN12897.1 putative CP/RdRp } \\
\text { [Zygosaccharomyces bailii } \\
\text { virus Z] }\end{array}$ & 43 & $2 \mathrm{E}-12$ & $\begin{array}{l}\text { Rhodophyta; } \\
\text { Bacteria }\end{array}$ & $\begin{array}{l}\text { Marine } \\
\text { arthropod }\end{array}$ & Rhodophyta \\
\hline $\begin{array}{l}\text { Benthesicyme } \\
\text { durna-like virus }\end{array}$ & $\begin{array}{l}\text { MMETSP1319 } \\
\text { T. pacifica } \\
\text { (Bolidophyceae) }\end{array}$ & Partial & 404 & $\begin{array}{l}\text { QDH90748.1 RdRp, partial } \\
\text { [Partitiviridae sp.] }\end{array}$ & 29 & $1 \mathrm{E}-17$ & Bolidophyceae & Protist & Bolidophyceae \\
\hline $\begin{array}{l}\text { Herophile durna- } \\
\text { like virus }\end{array}$ & $\begin{array}{l}\text { MMETSP0140 } \\
\text { P. australis } \\
\text { (Bacillariophyta) }\end{array}$ & Partial & 10 & $\begin{array}{c}\text { QOW97238.1 RdRp } \\
\text { [Amalga-like lacheneauvirus] }\end{array}$ & 27 & $2 \mathrm{E}-19$ & Bacillariophyta & Chlorophyta & Bacillariophyta \\
\hline $\begin{array}{l}\text { Cymopoleia durna- } \\
\text { like virus }\end{array}$ & $\begin{array}{l}\text { MMETSP1081 } \\
P . \text { amylifera } \\
\text { (Chlorophyta) }\end{array}$ & Partial & 10 & $\begin{array}{c}\text { YP_009551448.1 RdRp } \\
\text { [Diatom colony associated } \\
\text { dsRNA virus 2] }\end{array}$ & 31 & $2 \mathrm{E}-34$ & Chlorophyta & Fungi & Chlorophyta \\
\hline
\end{tabular}




\begin{tabular}{|c|c|c|c|c|c|c|c|c|c|}
\hline $\begin{array}{l}\text { Ourea durna-like } \\
\text { virus }\end{array}$ & $\begin{array}{l}\text { MMETSP0797 } \\
\text { D. acuminata } \\
\text { (Dinophyceae) }\end{array}$ & Partial & 4 & $\begin{array}{c}\text { ARO72610.1 RdRp } \\
\text { [Spinach deltapartitivirus 1] }\end{array}$ & 27 & $4 \mathrm{E}-11$ & $\begin{array}{l}\text { Dinophyceae; } \\
\text { Bacteria }\end{array}$ & Land plant & Dinophyceae \\
\hline $\begin{array}{l}\text { Aegean partiti-like } \\
\text { virus }\end{array}$ & $\begin{array}{l}\text { MMETSP0491 } \\
\text { T. chuii } \\
\text { (Chlorophyta) }\end{array}$ & $\begin{array}{l}\text { Full- } \\
\text { length }\end{array}$ & 3296 & $\begin{array}{c}\text { QOW97235.1 RdRp } \\
\text { [Partiti-like lacotivirus] }\end{array}$ & 29 & $6 \mathrm{E}-62$ & Chlorophyta & Chlorophyta & Chlorophyta \\
\hline $\begin{array}{l}\text { Pelias marna-like } \\
\text { virus }\end{array}$ & $\begin{array}{l}\text { MMETSP1377 } \\
\text { Symbiodinium sp. } \\
\text { (Dinophyceae) }\end{array}$ & $\begin{array}{l}\text { Full- } \\
\text { length }\end{array}$ & 60553 & $\begin{array}{l}\text { YP_009337401.1 hypothetical } \\
\text { protein } 2 \\
\text { [Wenzhou picorna-like virus } 4]\end{array}$ & 26 & $8 \mathrm{E}-98$ & Dinophyceae & Algae & Xanthophyceae \\
\hline $\begin{array}{l}\text { Neleus marna-like } \\
\text { virus, } 1\end{array}$ & $\begin{array}{c}\text { MMETSP0946 } \\
\text { V. litorea } \\
\text { (Xanthophyceae) }\end{array}$ & $\begin{array}{l}\text { Full- } \\
\text { length }\end{array}$ & 806763 & $\begin{array}{c}\text { YP_009336927.1 hypothetical } \\
\text { protein } 1 \\
\text { [Shahe picorna-like virus 3] }\end{array}$ & 33 & $3 \mathrm{E}-180$ & Vaucheriaceae & Algae & Xanthophyceae \\
\hline $\begin{array}{l}\text { Neleus marna-like } \\
\text { virus, } 2\end{array}$ & $\begin{array}{c}\text { MMETSP0945 } \\
\text { V. litorea } \\
\text { (Xanthophyceae) }\end{array}$ & $\begin{array}{l}\text { Full- } \\
\text { length }\end{array}$ & 711119 & $\begin{array}{c}\text { YP_009336927.1 hypothetical } \\
\text { protein 1 } \\
\text { [Shahe picorna-like virus 3] }\end{array}$ & 33 & $4 \mathrm{E}-180$ & Vaucheriaceae & Algae & Xanthophyceae \\
\hline \multirow{3}{*}{$\begin{array}{l}\text { Tyro marna-like } \\
\text { virus }\end{array}$} & $\begin{array}{l}\text { MMETSP0905 } \\
\text { T. antarctica } \\
\text { (Bacillariophyta) }\end{array}$ & Partial & 126 & \multirow{3}{*}{$\begin{array}{c}\text { YP_001429582.1 hypothetical } \\
\text { protein JP-A_gp2 } \\
\text { [Marine RNA virus JP-A] }\end{array}$} & \multirow{3}{*}{75} & \multirow{3}{*}{$3 E-272$} & \multirow{3}{*}{$\begin{array}{l}\text { Bacillariophyta; } \\
\text { Bacteria }\end{array}$} & \multirow{3}{*}{ Algae } & \multirow{3}{*}{ Bacillariophyta } \\
\hline & $\begin{array}{l}\text { MMETSP0903 } \\
\text { T. antarctica } \\
\text { (Bacillariophyta) }\end{array}$ & Partial & 2034 & & & & & & \\
\hline & $\begin{array}{l}\text { MMETSP0902 } \\
\text { T. antarctica } \\
\text { (Bacillariophyta) }\end{array}$ & Partial & 237 & & & & & & \\
\hline $\begin{array}{l}\text { Aloadae toti-like } \\
\text { virus, } 1\end{array}$ & $\begin{array}{l}\text { MMETSP1388 } \\
\text { Isochrysis } \\
\text { (Haptophyta) }\end{array}$ & Partial & 39 & $\begin{array}{c}\text { QIJ70132.1 RdRp } \\
\text { [Keenan toti-like virus] }\end{array}$ & 33 & 2E-109 & Haptophyta & $\begin{array}{c}\text { Fungi } \\
\text { /Invertebrates }\end{array}$ & Haptophyta \\
\hline $\begin{array}{l}\text { Aloadae toti-like } \\
\text { virus, } 2\end{array}$ & MMETSP1090 & Partial & 11 & $\begin{array}{c}\text { QIJ70132.1 RdRp } \\
\text { [Keenan toti-like virus] }\end{array}$ & 33 & 2E-109 & Haptophyta & $\begin{array}{c}\text { Fungi } \\
\text { /Invertebrates }\end{array}$ & Haptophyta \\
\hline
\end{tabular}




\begin{tabular}{|c|c|c|c|c|c|c|c|c|c|}
\hline & $\begin{array}{c}\text { Isochrysis } \\
\text { (Haptophyta) }\end{array}$ & & & & & & & & \\
\hline $\begin{array}{l}\text { Antaeus toti-like } \\
\text { virus, } 1\end{array}$ & $\begin{array}{c}\text { MMETSP0154 } \\
T . \text { antarctica } \\
\text { (Bacillariophyta) }\end{array}$ & $\begin{array}{l}\text { Full- } \\
\text { length }\end{array}$ & 27 & $\begin{array}{l}\text { QGY72637.1 putative coat } \\
\text { protein [Plasmopara viticola } \\
\text { associated totivirus-like 2] }\end{array}$ & 22 & $1 \mathrm{E}-10$ & Bacillariophyta & Protist & Bacillariophyta \\
\hline $\begin{array}{l}\text { Antaeus toti-like } \\
\text { virus, } 2\end{array}$ & $\begin{array}{c}\text { MMETSP0152 } \\
T . \text { antarctica } \\
\text { (Bacillariophyta) }\end{array}$ & $\begin{array}{l}\text { Full- } \\
\text { length }\end{array}$ & 7 & $\begin{array}{l}\text { BBJ21451.1 CP-RdRp fusion } \\
\text { protein } \\
\text { [Pythium splendens RNA virus } \\
\text { 1] }\end{array}$ & 40 & $5 \mathrm{E}-53$ & Bacillariophyta & Protist & Bacillariophyta \\
\hline \multirow{4}{*}{$\begin{array}{c}\text { Charybdis toti-like } \\
\text { virus }\end{array}$} & $\begin{array}{l}\text { MMETSP0853 } \\
\text { P. fraudulenta } \\
\text { (Bacillariophyta) }\end{array}$ & Partial & 38 & \multirow{4}{*}{$\begin{array}{c}\text { YP_003288763.1 RdRp } \\
\text { [Rosellinia necatrix } \\
\text { megabirnavirus 1/W779] }\end{array}$} & \multirow{4}{*}{30} & \multirow{4}{*}{$4 \mathrm{E}-24$} & \multirow{4}{*}{$\begin{array}{c}\text { Bacillariophyta; } \\
\text { Bacteria }\end{array}$} & \multirow{4}{*}{ Fungi } & \multirow{4}{*}{ Bacillariophyta } \\
\hline & $\begin{array}{l}\text { MMETSP0851 } \\
\text { P.fraudulenta } \\
\text { (Bacillariophyta) }\end{array}$ & Partial & 44 & & & & & & \\
\hline & $\begin{array}{l}\text { MMETSP0850 } \\
\text { P. fraudulenta } \\
\text { (Bacillariophyta) }\end{array}$ & Partial & 41 & & & & & & \\
\hline & $\begin{array}{l}\text { MMETSP0852 } \\
\text { P.fraudulenta } \\
\text { (Bacillariophyta) }\end{array}$ & Partial & 14 & & & & & & \\
\hline $\begin{array}{c}\text { Chrysaor toti-like } \\
\text { virus }\end{array}$ & $\begin{array}{c}\text { MMETSP0418 } \\
\text { A. radiata } \\
\text { (Bacillariophyta) }\end{array}$ & Partial & 40 & $\begin{array}{c}\text { YP_009551502.1 RdRp } \\
\text { [Diatom colony associated } \\
\text { dsRNA virus } 17 \text { genome type } \\
\text { B] }\end{array}$ & 27 & 9E-95 & $\begin{array}{c}\text { Bacillariophyta; } \\
\text { Bacteria }\end{array}$ & Soil & Bacillariophyta \\
\hline $\begin{array}{l}\text { Laestrygon toti-like } \\
\text { virus }\end{array}$ & $\begin{array}{l}\text { MMETSP1451 } \\
\text { V. brassicaformis } \\
\text { (Chromeraceae) }\end{array}$ & Partial & 29 & $\begin{array}{c}\text { YP_009551504.1 RdRp } \\
\text { [Diatom colony associated } \\
\text { dsRNA virus } 17 \text { genome type } \\
\text { A] }\end{array}$ & 34 & $4 \mathrm{E}-112$ & Chromeraceae & Soil & Chromeraceae \\
\hline
\end{tabular}




\begin{tabular}{|c|c|c|c|c|c|c|c|c|c|}
\hline Arion toti-like virus & $\begin{array}{l}\text { MMETSP0796 } \\
P . \text { bahamense } \\
\text { (Dinophyceae) }\end{array}$ & Partial & 31 & $\begin{array}{l}\text { QGA70930.1 RdRp } \\
\quad \text { [Ahus virus] }\end{array}$ & 25 & $3 \mathrm{E}-18$ & $\begin{array}{l}\text { Dinophyceae; } \\
\text { Bacteria }\end{array}$ & $\begin{array}{c}\text { Protist/ } \\
\text { Marine host }\end{array}$ & Dinophyceae \\
\hline Otus toti-like virus & $\begin{array}{l}\text { MMETSP0011 } \\
\text { R. marinus } \\
\text { (Rhodophyta) }\end{array}$ & $\begin{array}{l}\text { Full- } \\
\text { length }\end{array}$ & 31 & $\begin{array}{c}\text { AMB17469.1 RdRp, partial } \\
\text { [Delisea pulchra totivirus IndA] }\end{array}$ & 51 & $3 \mathrm{E}-120$ & $\begin{array}{l}\text { Rhodophyta; } \\
\text { Bacteria }\end{array}$ & Fungi & Rhodophyta \\
\hline $\begin{array}{l}\text { Polyphemus toti- } \\
\text { like virus }\end{array}$ & $\begin{array}{c}\text { MMETSP0418 } \\
\text { A. radiata } \\
\text { (Bacillariophyta) }\end{array}$ & Partial & 10 & $\begin{array}{c}\text { YP_009552789.1 RdRp } \\
\text { [Diatom colony associated } \\
\text { dsRNA virus 5] }\end{array}$ & 59 & $3 \mathrm{E}-79$ & $\begin{array}{l}\text { Bacillariophyta; } \\
\text { Bacteria }\end{array}$ & $\begin{array}{l}\text { Algae/ } \\
\text { Protist }\end{array}$ & Bacillariophyta \\
\hline $\begin{array}{l}\text { Ephialtes toti-like } \\
\text { virus }\end{array}$ & $\begin{array}{c}\text { MMETSP0418 } \\
\text { A. radiata } \\
\text { (Bacillariophyta) }\end{array}$ & Partial & 13 & $\begin{array}{c}\text { YP_009552789.1 RdRp } \\
\text { [Diatom colony associated } \\
\text { dsRNA virus 5] }\end{array}$ & 63 & $1 \mathrm{E}-200$ & $\begin{array}{l}\text { Bacillariophyta; } \\
\text { Bacteria }\end{array}$ & $\begin{array}{l}\text { Algae/ } \\
\text { Protist }\end{array}$ & Bacillariophyta \\
\hline
\end{tabular}


Notably, all the RdRps identified in the BLAST analysis exhibited very high levels of sequence divergence, with median pairwise identity values of only $\sim 35 \%$ to the closest known virus homolog (Table 1). In addition, with the exceptions of Pelias marna-like virus and Neleus marna-like virus, the newly described viral sequences were at relatively low abundance all (Table 1). This may reflect the lack of an rRNA depletion step used in the MMETSP library preparation, such that any RNA viruses would necessarily only represent a small proportion of reads. To shed more light on this issue, we compared levels of virus abundance with the expression levels of a host gene - that encoding the large subunit of the Ribulose-1,5-Bisphosphate Carboxylase/Oxygenase ( $r b c L$ ) (Figure S1, Table S4). The $r b c L$ gene is commonly used as a diversity marker in algae ${ }^{33}$, and sequences are available for all the microalgal species used here. Overall, the number of reads mapping to putative RNA viruses are in the same order of magnitude or higher than those reported for the host $r b c L$ gene (Figure S1), compatible with their designation as replicating viruses.

\subsection{Additional cellular organisms in the transcriptome data}

We used mono-strain cultures of microbial eukaryotes to investigate the relationship among RNA viruses and their hosts. While the lack of additional eukaryotic organisms (fungi, other protists) was supposedly ensured under the MMETSP project guidelines, with 18S rRNA sequencing of each culture ${ }^{15}$, some caveats remain for non-axenic cultures (Table S5). Indeed, some cultures likely contain contaminating Bacteria or Archaea, sometimes as intracellular parasites or as obligate mutualists in the culture media ${ }^{5}$. To assess this, contigs from libraries positive for RNA viruses were submitted to BLASTn and BLASTx. The ratio of assigned contigs and their kingdom assignments are summarized Figure 3 and used to infer the likely host organisms (Table 1). 
A)

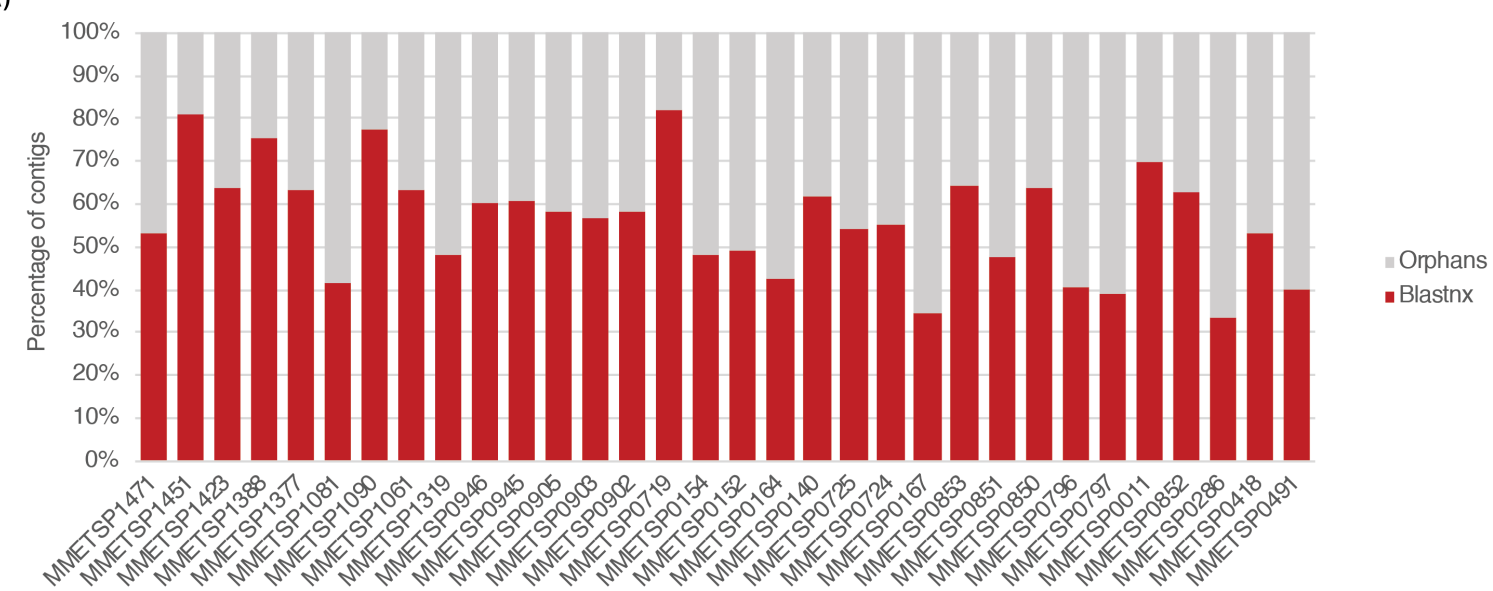

B)

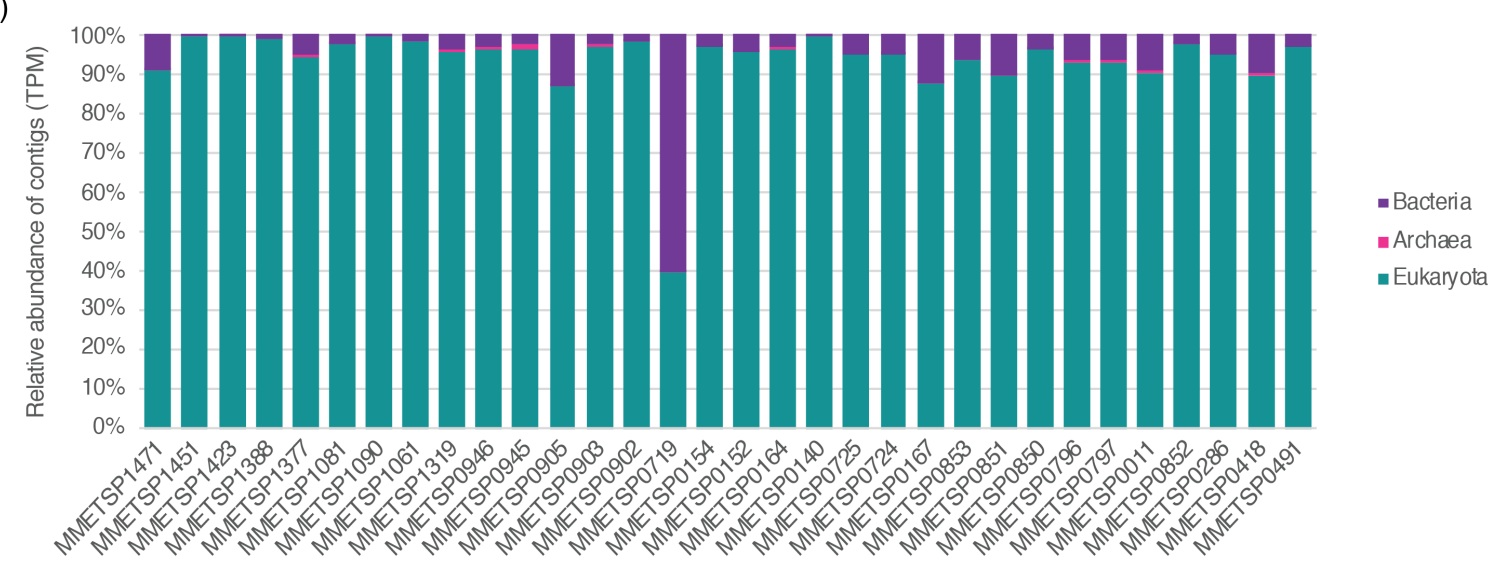

Figure 3. Taxonomic assignment of contigs in RNA virus positive MMETSP libraries. (A) Ratio of contigs with hits to the nt and $\mathrm{nr}$ databases (red) versus orphans contigs (grey). (B) Relative abundance of cellular organism-like contigs based on the taxonomic assignment of their closest homologs in the $\mathrm{nr}$ and nt databases at the kingdom level. Contig abundances are calculated as transcripts per million (TPM). approaches (Figure 3A), with prokaryotic organisms on average representing less than 10\% of assigned contigs (Figure 3B). However, the MMETSP0719 containing C. curvisetus (Bacillariophyta) is enriched with co-infecting bacteria. According to the BLASTn/BLASTp entries obtained for this sample, this seems largely due to the presence of the marine alphaproteobacteria Jannaschia. This is to be expected as some algal species require the presence of particular bacterial species to obtain essential nutrients ${ }^{34}$. 


\subsection{Distribution and prevalence of RNA viruses in MMETSP cultured strains}

264

265

266

267

268

We found evidence for RNA viruses - that is, hits to the viral RdRp - in eight of the 19 major groups of microalgae, without detectable virus/algal taxon specificity (Figure 4).

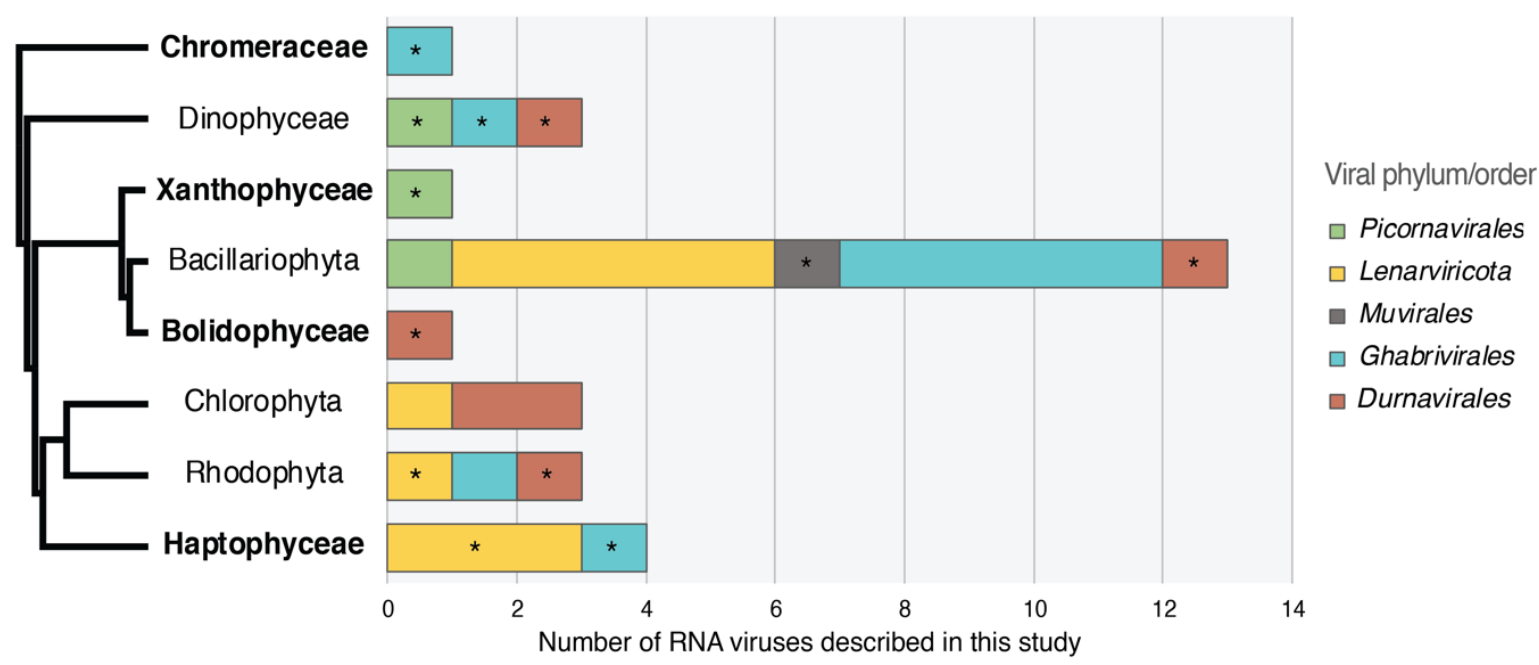

Figure 4. Distribution of RNA virus groups identified in algae. Only algal lineages containing RNA virus RdRps are shown. Left, cladogram of the algal host lineages positive for RNA viruses. Taxa for which no RNA viruses have previously been reported are indicated in bold. Right, total counts of newly described RNA viral sequences in each algal taxon (including viruses observed in several samples from the same taxa). *First observation of this virus taxon in the corresponding algal clade. The levi-like sequence that likely infects a bacterial host was excluded.

The distribution of RNA viruses is highly heterogeneous among the microalgae studied here, with a large representation in the Bacillariophyta, Dinophyceae and Haptophyceae, with only few or no viruses in the other taxa analyzed here (Figure 4). It is important to note that the number of viruses is strongly associated with the number of libraries analysed and thus likely depicts a limit of detection imposed by small sample sizes in some groups (i.e. large numbers of transcriptomes are available for the Bacillariophyta, Dinophyceae and Haptophyceae).

\subsection{Positive-sense RNA viruses (ssRNA+)}

Eleven of the 30 viruses discovered in this study show clear homology to three of the four families that comprise the recently classified phylum Lenarviricota of ssRNA+ viruses: the 

and leading us to propose that these 11 sequences are novel viral species (Table 1).

\subsubsection{Narnaviridae-like sequences}

Three RdRp-containing contigs - denoted Amphitrite narna-like virus, Poseidon narna-like positions in a phylogeny of this virus family (Figure 2 and Figure 5).

While the closest homologs of these narna-like viruses were identified in fungi, oomycete (protist) and marine arthropod samples, all three samples that contain these viruses are Bacillariophyta species (A. radiata and P. pungens) (Table 1, Figure 5). As their genome sequences share $\sim 12 \%$ pairwise identity with other Narnaviridae we propose that Amphitrite narna-like virus, Poseidon narna-like virus and Halia narna-like virus represent novel species within the genus Narnavirus.

\subsubsection{Mitoviridae-like sequences}

Seven RdRp protein sequences, retrieved from diverse algae host lineages - Rhodophyta,

(Figure 5). According to their placement in the Mitoviridae phylogeny as well as their level of divergence to existing mitoviruses (Figure 5, Table 1), these seven new viruses are potential members of the genus Mitovirus. All these mitovirus-like sequences have similar genome organizations, with the exception of one putative mitovirus with a genome that seemingly encodes a single RdRp-containing ORF (Figure 5). It is also notable that the mito-like virus can only be predicted using the mitochondrial code (Figure 5). 
bioRxiv preprint doi: https://doi.org/10.1101/2021.05.09.443335; this version posted May 10, 2021. The copyright holder for this preprint (which was not certified by peer review) is the author/funder, who has granted bioRxiv a license to display the preprint in perpetuity. It is made available under aCC-BY-ND 4.0 International license.

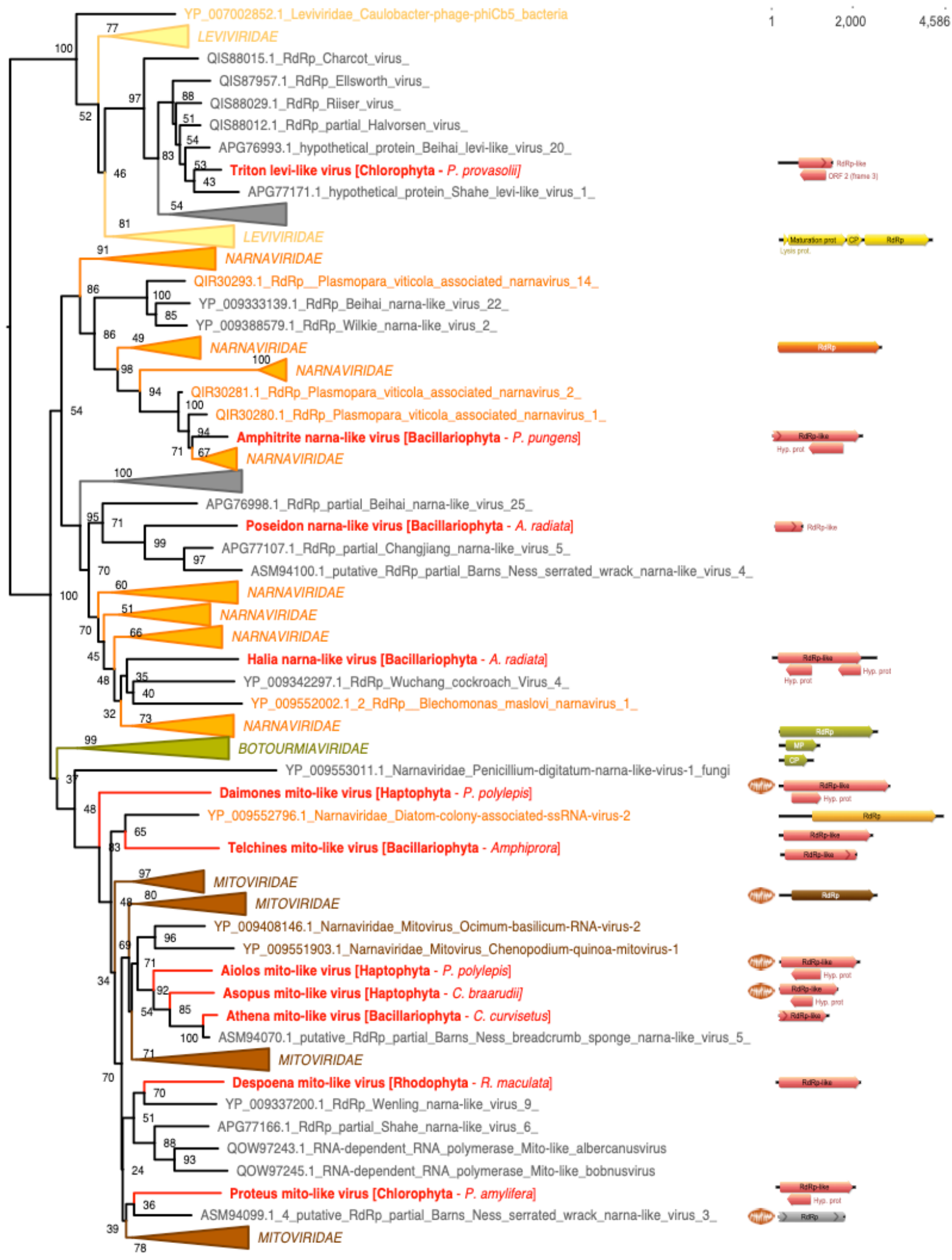

311 Figure 5. Phylogenetic position of the newly described RNA virus sequences in the 312 phylum Lenarviricota. Left: ML phylogeny of the Lenaviricota RdRp (LG+F+R8 amino 
acid substitution model). Newly described viruses are shown in red. Algal host taxa are specified in brackets. Branch labels = bootstrap support (\%). The tree is mid-point rooted for clarity only. Right: genomic organisation of the newly described viruses (red), closest homologs and Lenarviricota RefSeq representatives: Cassava virus C (NC_013111; Botourmiaviridae), Saccharomyces 23S RNA (NC_004050; Narnaviridae), Acinetobacter phage AP205 (NC_002700; Leviviridae), Chenopodium quinoa mitovirus 1 (NC_040543; Mitoviridae). ORFs translated with the mitochondrial genetic code are marked a mitochondria icon. For clarity, some lineages were collapsed (a non-collapsed version of the tree is available as Supplementary Information).

\subsubsection{Leviviridae-like sequences}

One viral RdRp-like hit, in the Chlorophyta species Pycnococcus provasolii, is related to some bacteria-infecting Leviviridae and based on the levels of sequence identity this likely constitutes a new genus in this family (Table 1). As there were some bacterial reads in the Pycnococcus provasolii samples (MMETSP1471) (Figure 3B), it is likely that this Triton levi-like virus sequence infects bacteria (Actinobacteria or Proteobacteria-like) also present in the culture rather than Pycnococcus provasolii.

\subsubsection{Picornavirales-like sequences}

Three sequences - denoted Pelias marna-like virus, Neleus marna-like virus and Tyro marnalike virus - were identified in diverse cultures belonging to various taxa (Figure 4): Symbiodinium sp. (Dinophyceae), V. litorea (Xanthophyceae) and T. antarctica (Bacillariophyta). These viruses exhibit sequence similarity with ssRNA+ viruses from the order Picornavirales. Specifically, they fell within the large algal associated family Marnaviridae (Figure 2C) and based on their respective positions in the phylogeny and the level of sequence divergence, Pelias marna-like virus could constitute a new genus in the Marnaviridae, while Neleus marna-like virus and Tyro marna-like virus are likely members of the genera Kusarnavirus and Sogarnavirus, respectively (Figure 6, Table 1). They also seem to share similar genome lengths and organizations as their closest relatives (Figure 6). 


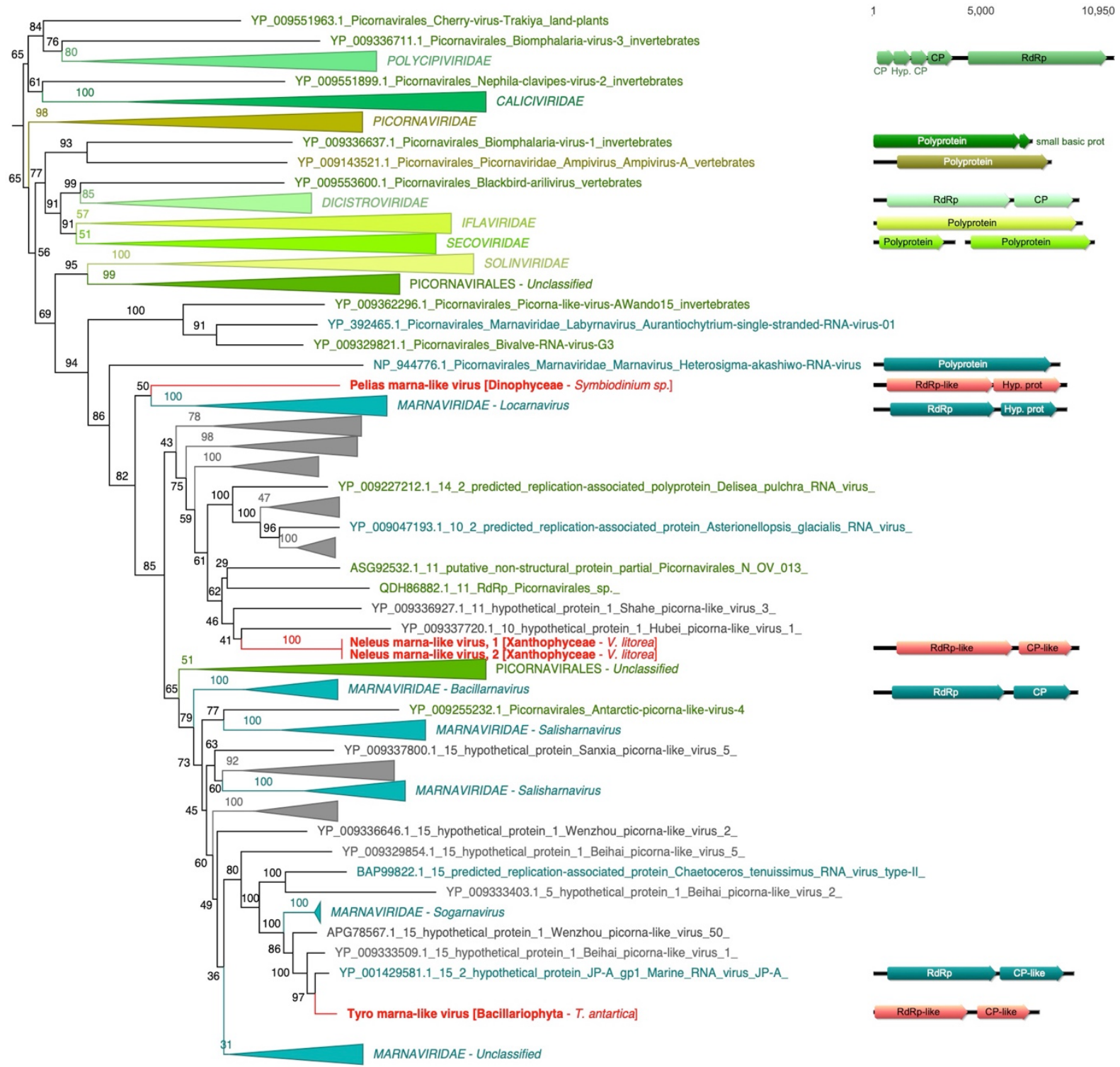

343 Figure 6. Phylogenetic placement of the newly described RNA virus sequences in the

344 order Picornavirales. Left, ML phylogeny of the Picornaviruses RdRp (assuming the

345 LG+F+R10 amino acid substitution model). Newly described viruses are indicated in red.

346 Algae host taxon and species are specified in brackets. Branch labels = bootstrap support (\%).

347 The tree is mid-point rooted for clarity only. Right, genomic organisation of newly described

348 viruses (red), closest homologs and the following Picornavirales order RefSeq

349 representatives: Solenopsis invicta virus 2 (NC_039236; Polycipiviridae), Porcine enteric sapovirus (NC_000940; Caliciviridae), Foot-and-mouth disease virus - type O (NC_039210; Picornaviridae), Acute bee paralysis virus (NC_002548; Dicistroviridae), Infectious flacherie virus (NC_003781; Iflaviridae), Cowpea severe mosaic virus (NC_003544/NC_003545; Secoviridae). For clarity, some lineages were collapsed (a noncollapsed version of the tree is available as Supplementary Information). 


\subsection{Double-stranded (dsRNA) viruses}

356 Almost a third of the RNA viruses newly reported here were related to dsRNA viruses of the family Totiviridae (Figure 2D). The single exception was the more divergent Charybdis totilike virus, the exact placement of which within the order Ghabrivirales was unclear as it occupied a basal position in the phylogenetic tree and showed only low levels of sequence similarity to related viruses ( $\sim 30 \%$ at RdRp protein level) (Figure 7 , Table 1$)$.

Aloadae toti-like virus, found in Haptophyta Isochrysis sp, groups with the protistassociated Giardiavirus genus of the Totiviridae, and more surprisingly with Keenan toti-like virus recently identified in ectoparasitic flies (Figure 7), although with very high levels of sequence divergence (Table 1). Similarly, Chrysaor toti-like virus, Laestrygon toti-like virus and Arion toti-like virus, retrieved from Bacillariophyta, Chromerid and Dinophyceae, respectively, form a clade with Totiviridae-like sequences identified in either marine arthropods or oomycete protists (Figure 7). While these likely constitute a newly genus within the Totiviridae, their host remains uncertain. Antaeus toti-like virus, retrieved from the Bacillariophyta T. antarctica, groups with Pythium polare RNA virus 1 that infects the oomycete Pythium polare, confirming the presence of a polar stramenopile clade in the Totiviridae. Otus toti-like virus, identified in the Rhodophyta R. marinus, clusters $(51 \%$ sequence identity) with the Delisea pulchra totivirus identified in the Rhodophyta (Figure 7). virus - were identified in A. radiata (Bacillariophyta) and, together with the diatom colony associated dsRNA viruses, form a new dsRNA viral clade, and likely genus, specifically associated with Bacillariophyta (diatoms) (Figure 7).

Strong similarities in genome organization were observed between the Otus toti-like virus and Antaeus toti-like virus and their toti-like homologs, with a potential single segment encoding a coat protein (CP) in 5' and a RdRp in 3' (Figure 7). As Charybdis toti-like virus, 
Chrysaor toti-like virus, Laestrygon toti-like virus, Arion toti-like virus, Polyphemus toti-like virus and Ephialtes toti-like virus all had partial genomes we were unable to determine their genomic organization, aside from the observation that they are likely unsegmented as they fall within the unsegmented Totiviridae. Unfortunately, such an assumption cannot be made for Charybdis toti-like virus, because of its basal position within the Ghabrivirales. position (Figure 8). Moreover, these sequences seemingly have no association with specific microalgal groups, being observed in species of Rhodophyta, Bolidophyceae, and Figure 8$)$ and displays a moderate level of sequence divergence ( $43 \%$ identity in the RdRp) with Zygosaccharomyces bailii virus $Z$ identified in fungi (Table 1). Whether this constitutes a new genus within the Amalgaviridae remains to be determined. like chassivirus, both previously identified in cultures of Ostreobium sp. (Chlorophyta), and that fell between the Amalgaviridae and Partitiviridae families in our phylogenetic analysis

400 (Figure 8). The genomic sequences for Benthesicyme durna-like virus, Herophile durna-like virus and Cymopoleia durna-like virus were likely partial such that their organization, 
bioRxiv preprint doi: https://doi.org/10.1101/2021.05.09.443335; this version posted May 10, 2021. The copyright holder for this preprint (which was not certified by peer review) is the author/funder, who has granted bioRxiv a license to display the preprint in perpetuity. It is made available under aCC-BY-ND 4.0 International license.
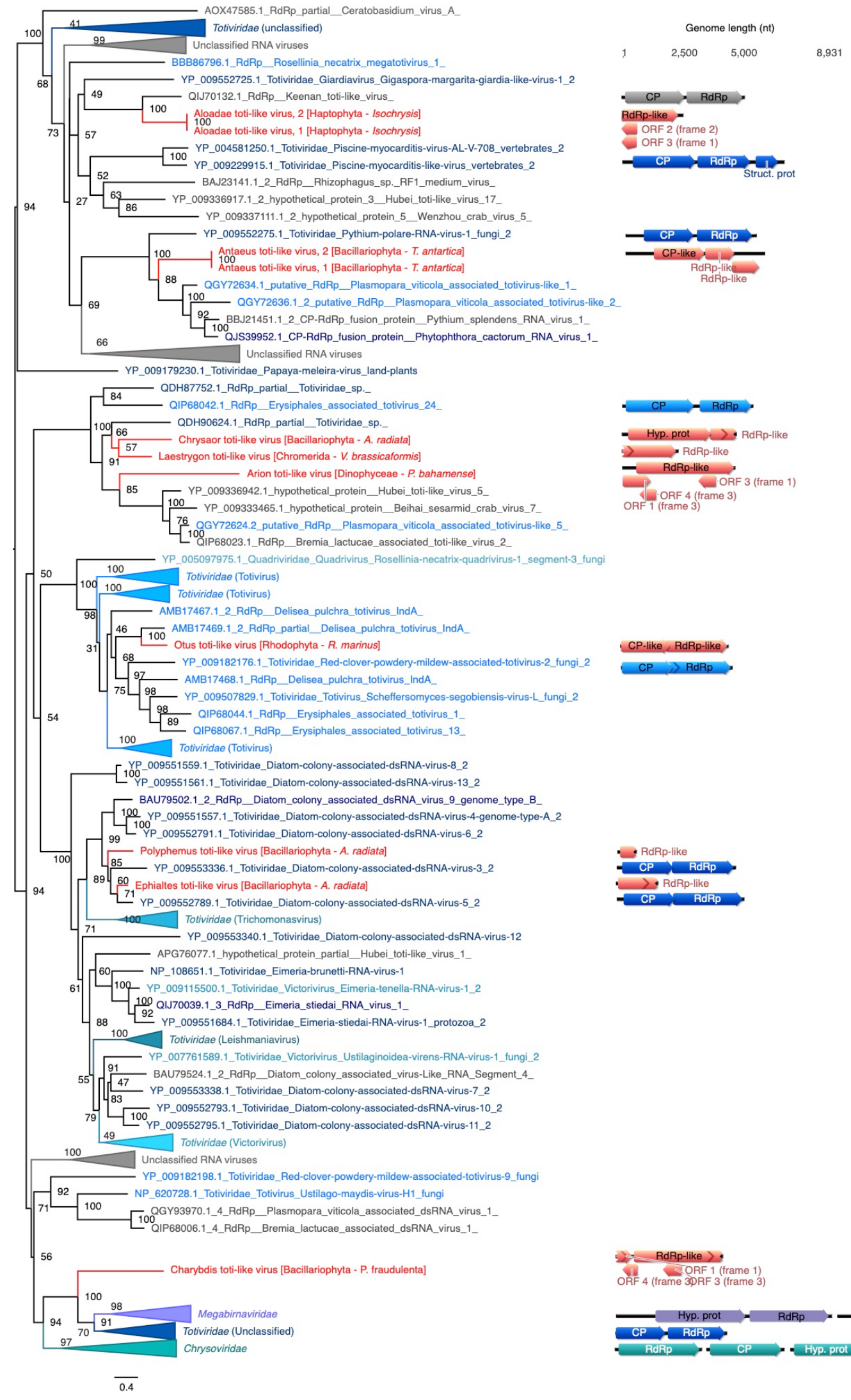

CP-like, RdRp-like,
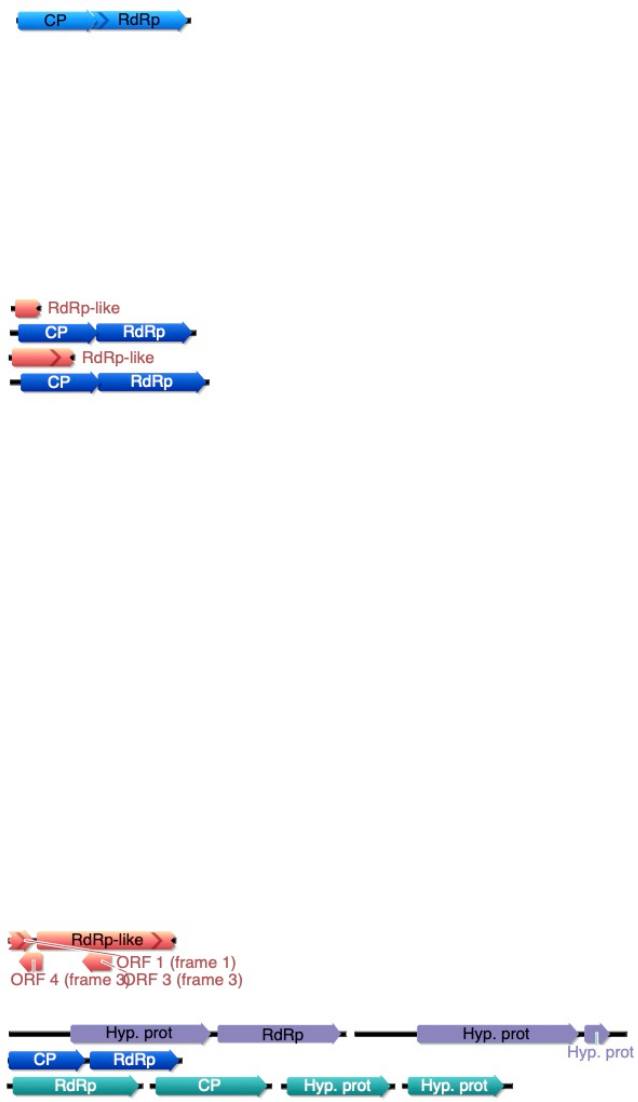

Figure 7. Phylogenetic position of the newly described RNA virus sequences among the

406 amino acid substitution model). Newly described viruses are indicated in red. Algae host taxon and species are specified in brackets. Branch labels = bootstrap support (\%). The tree is 
mid-point rooted for clarity only. Right, genomic organisation of the newly described viruses (red), closest homologs and the following representative Ghabrivirales: Rosellinia necatrix megabirnavirus 1/W779 (NC_013462/NC_013463; Megabirnaviridae), Tuber aestivum virus 1 (NC_038698; Totiviridae), Penicillium chrysogenum virus (NC_007539/NC_007540/NC_007541/NC_007542; Chrysoviridae). For clarity, some lineages were collapsed (a non-collapsed version of the tree is available as Supplementary 414 Material).

Aegean partiti-like virus falls in the Partitiviridae, grouping with the Partiti-like

417 lacotivirus, Partiti-like allasinovirus, Partiti-like Adriusvirus and Bryopsis cinicola

chloroplast dsRNA (BDRC): these are all Partitiviridae and associated with Ulvophyceae

algae (Figure 8). The presence of Aegean partiti-like virus in Tetraselmis chuii (Chlorophyta) strongly supports the existence of a Chlorophyta-infecting partiti-like viral genus. Assuming a homologous genome organization, the genome of Aegean partiti-like virus would comprise a single segment encoding a $\mathrm{RdRp}$ in its 5' region as well as a hypothetical protein, potentially a coat protein, in the 3 ' region. Whether Aegean partiti-like virus is associated with the host chloroplast remains uncertain. Finally, Ourea durna-like virus is highly divergent and falls basal to the bi-segmented Partitiviridae (Figure 8). However, considering the length and the single ORF organization of the partial genomic sequence retrieved, it is likely that a second segment encoding a CP may not have been detected by BLAST due to very high levels of sequence divergence. 

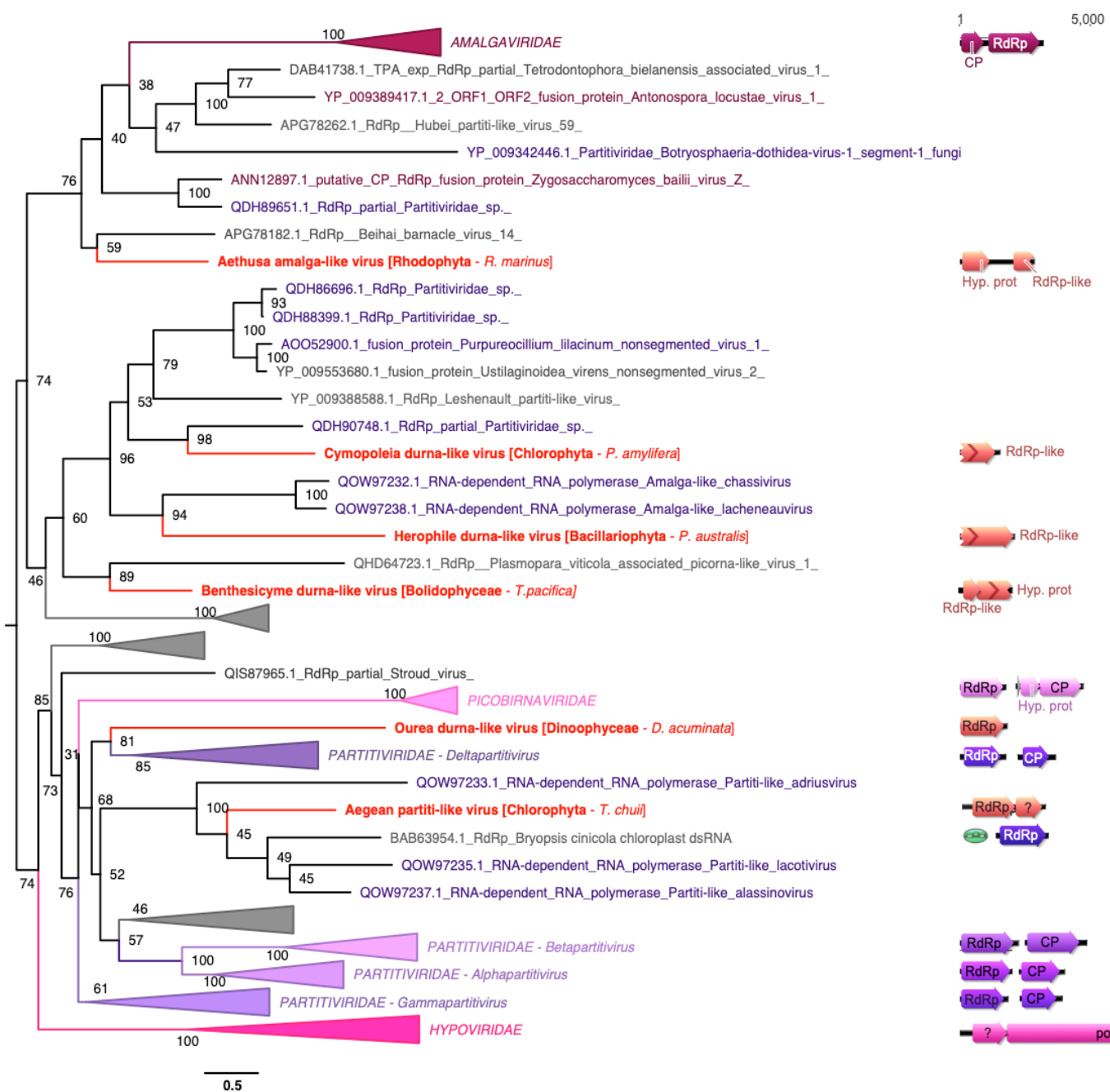

Figure 8. Phylogenetic positions of the newly described RNA viruses among the amino acid substitution model). Newly described viruses are indicated in red. Algae host taxon and species are specified in brackets. Branch labels = bootstrap support (\%). The trees are mid-point rooted for clarity only. Right, genomic organisation of newly-discovered viruses (red), closest homologs and the following Partiti-picobirna super-clade representatives: Zygosaccharomyces bailii virus Z (NC_003874; Amalgaviridae), Cryphonectria hypovirus 2 (NC_003534; Hypoviridae), Chicken picornavirus (NC_003534/ NC_040438; Picobirnaviridae), Fig cryptic virus (NC_015494/NC_015495; Deltapartitivirus), Discula destructiva virus 1 (NC_002797/NC_002 800 ; Gammapartitivirus), Ceratocystis resinifera virus 1 (NC_010755/NC_010754; Betapartitivirus), White clover cryptic virus 1 (NC_006275/NC_006276; Alphapartitivirus). ORFs translated with the plastid genetic code are labelled with a green plastid. For clarity, some lineages were collapsed (a non-collapsed version of the tree is available as Supplementary Information).

Negative-sense viruses (ssRNA-)

446 A novel RdRp sequence, Susy yue-like virus, was identified in the Pseudo-nitzschia heimii

447 (Bacillariophyta) culture. This virus clusters among the ssRNA- Haploviricotina, falling 

although the functional implications of this alternative motif are unclear.

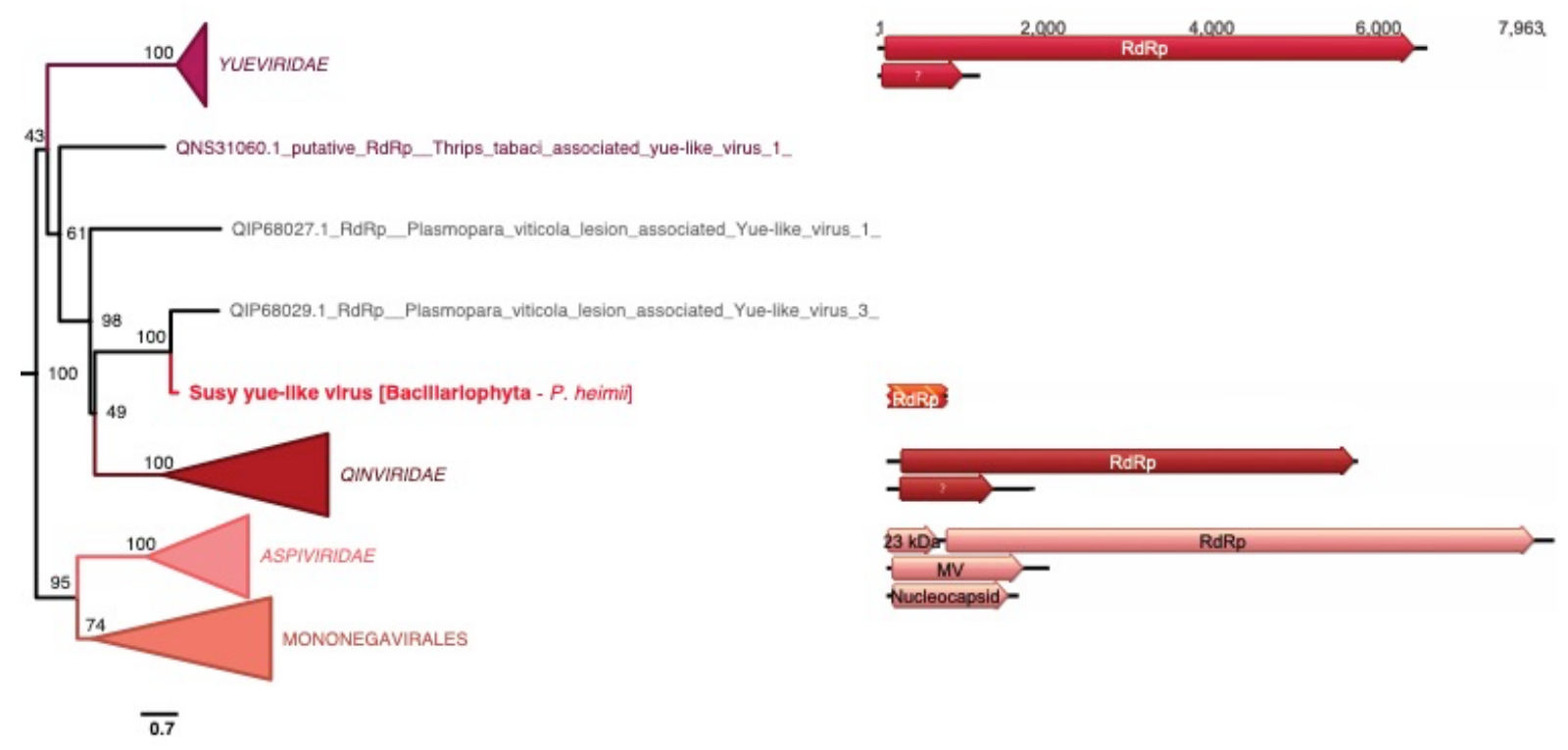

Figure 9. Position of the newly described RNA virus in the phylum Haploviricotina. Left, ML phylogeny of the Haploviricotinia RdRp (employing the LG+F+R10 amino acid substitution model). The virus newly described here is shown in red. Algae host taxon and species are specified in brackets. Branch labels = bootstrap support (\%). The tree is mid-point rooted for clarity only. Right, genomic organisation of the newly described virus (red) and the following homologs representatives: Shahe yuevirus-like virus 1 (NC 033289/NC 033290; Yueviridae), Beihai sesarmid crab virus 4 (NC_032274/NC_032272; Qinviridae), Blueberry mosaic associated virus (NC_033754/NC_036634/NC_036-635; Aspiviridae). For clarity, some lineages were collapsed (a non-collapsed version of the tree is available as Supplementary Information).

\section{Detection of divergent RNA viruses based on RdRp motifs and structural features}

The microalgal transcriptomes sequenced as part of the MMETSP likely contain viruses that 
protein functional motifs and structural features on all the BLAST-unannotated sequences: this accounted for $10-34 \%$ of the total predicted ORFs of at least 200 amino acid residues in length (Figure S2).

A very large proportion of the sequences retained from our combined RdRp-based HMM, InterproScan analysis were false-positive hits as they were either confidently detected as eukaryotic-like sequences using Phyre2 or were too distant to be safely considered as an RdRp (i.e. unreliable alignment and no detection of RdRp catalytic motifs) (Table S3).

However, five RdRp-like candidates were retained from the manual curation steps. While no robust RdRp-like signal could be detected using Phyre2 (i.e. prediction confidence scores below 90\%) (Table S3), the presence of a significant HMM-detected homology with the PROSITE PS50507 profile (i.e. RdRp of ssRNA+ virus catalytic domain profile; Table S2) enabled us to further analyze these candidates as potential RdRp sequences. Four of these five RdRps came from the genus Bigelowiella, and three (MMETSP0045_DN12861, MMETSP1054_DN18666 and MMETSP1052_DN19445) shared high identity levels ( $>90 \%$ at both protein and nucleotide levels), while MMETSP1359_DN14104 shared only 70\% identity (Table 2). Although the PROSITE PS50507 profiles were built from ssRNA+ RdRp sequences, the IDD C-motif exhibited by these four RdRp-like candidates is found in the ssRNA-Qinviridae-like viruses as well as the new Susy yue-like virus found in Pseudo-nitzschia heimii (MMETSP1423). However, the nucleotide sequences of these RdRp-encoding contig candidates exhibited a strong match (evalue $<1$ E-90) with a genome contig (BIGNAscaffold_41_Cont1731) from the Bigelowiella natans genome (GCA_000320545.1). Hence, rather than representing an exogenous RNA virus, the distant RdRp hit in this case most likely constitutes an endogenous viral element (EVEs) indicative of a past, and likely ancient, infection event. 
Table 2. RdRp-like hits retrieved from the HMM-profile and Phyre2 analyses. Presence of the $\mathrm{A}, \mathrm{B}$ and $\mathrm{C}$ motifs are noted along with the sequence of the C-motif.

497

\begin{tabular}{|c|c|c|c|c|c|c|c|c|c|}
\hline Contig ID & Taxon & $\begin{array}{l}\text { RdRp } \\
\text { profile }\end{array}$ & $\begin{array}{c}\text { E- } \\
\text { valu } \\
\text { e }\end{array}$ & $\mathbf{A}$ & B & C & $\begin{array}{c}\text { Phyre2 } \\
\text { confid } \\
\%\end{array}$ & $\%$ ID & Hit info \\
\hline $\begin{array}{c}\text { MMETSP1359_DN141 } \\
\text { 04 } \\
\text { _c0_g1_i1_len843_1 }\end{array}$ & $\begin{array}{l}\text { Bigelowiella } \\
\text { longifila } \\
\text { (Cercozoa) }\end{array}$ & $\begin{array}{c}\text { PS5050 } \\
7\end{array}$ & $\begin{array}{c}6.0 \mathrm{E}- \\
07\end{array}$ & Yes & $?$ & IDD & 64.2 & 16 & $\begin{array}{l}\text { PDB header:t } \\
\text { ransferase }\end{array}$ \\
\hline $\begin{array}{c}\text { MMETSP0045_DN128 } \\
61 \\
\text { c0_g1_i1_len664_1 }\end{array}$ & $\begin{array}{l}\text { Bigelowiella } \\
\text { natans } \\
\text { (Cercozoa) }\end{array}$ & $\begin{array}{c}\text { PS5050 } \\
7\end{array}$ & $\begin{array}{c}8.7 \mathrm{E}- \\
06\end{array}$ & Yes & $?$ & IDD & 40.7 & 24 & $\begin{array}{l}\text { DNA/RNA } \\
\text { polymerases }\end{array}$ \\
\hline $\begin{array}{c}\text { MMETSP1054_DN186 } \\
66 \\
\text { c0_g1_i1_len657_1 }\end{array}$ & $\begin{array}{l}\text { Bigelowiella } \\
\text { natans } \\
\text { (Cercozoa) }\end{array}$ & $\begin{array}{c}\text { PS5050 } \\
7\end{array}$ & $\begin{array}{c}8.9 \mathrm{E}- \\
06\end{array}$ & Yes & $?$ & IDD & 41.6 & 24 & $\begin{array}{l}\text { DNA/RNA } \\
\text { polymerases }\end{array}$ \\
\hline $\begin{array}{c}\text { MMETSP1052_DN194 } \\
45 \\
\text { _c0_g1_i1_len738_1 }\end{array}$ & $\begin{array}{l}\text { Bigelowiella } \\
\text { natans } \\
\text { (Cercozoa) }\end{array}$ & $\begin{array}{c}\text { PS5050 } \\
7\end{array}$ & $\begin{array}{l}1.0 \mathrm{E}- \\
05\end{array}$ & Yes & $?$ & IDD & 40.4 & 24 & $\begin{array}{c}\text { DNA/RNA } \\
\text { polymerases }\end{array}$ \\
\hline $\begin{array}{c}\text { MMETSP0202_DN429 } \\
\text { 2 } \\
\text { c0_g1_i1_len814_1 }\end{array}$ & $\begin{array}{l}\text { Karenia brevis } \\
\text { (Dinophyceae) }\end{array}$ & $\begin{array}{c}\text { PS5050 } \\
7\end{array}$ & $\begin{array}{c}4.6 \mathrm{E}- \\
05\end{array}$ & Yes & $?$ & GDT & 56.7 & 17 & $\begin{array}{l}\text { PDB header: } \\
\text { hydrolase }\end{array}$ \\
\hline
\end{tabular}

499 In the case of the remote RdRp-like signal in MMETSP0202_DN4292, no GDT sequence at

500 motif $\mathrm{C}$ could be identified in an expansive $\mathrm{RdRp}$ data set $^{35}$. Hence, it is unclear if

501 MMETSP0202_DN4292 is a true viral RdRp or a false-positive hit.

\section{Discussion}

503 To the best of our knowledge we report the largest survey of RNA viruses in microalgal

504 curated cultures. With the discovery of 30 new and divergent viruses, 29 of which are likely

505 to infect algae species in which no viruses have previously been reported, this study greatly

506 extends our knowledge of the microalgae RNA virosphere. More broadly, this work

507 demonstrates the potential of protists to be major reservoirs of novel RNA viruses.

Despite the viral diversity documented, only 6\% (33 of 570) of the transcriptomes analysed here contained evidence of an RNA virus, far lower than equivalent meta-

510 transcriptomic studies of single organisms $s^{36-38}$. The use of purified cultures is expected to 
reduce the number of viruses compared to direct environmental samples, preventing the

512 sequencing of co-circulating viruses as well as those infecting other microorganisms in the

513 environment. However, this relative paucity of RNA viruses could also reflect

514 methodological limitations. First, the lack of rRNA depletion in the library processing leads a

515 concomitant reduction in the number of non-rRNA transcripts, including those from viruses.

516 Indeed, most of the viruses reported here display very low transcript abundance, suggesting

517 that additional RNA viruses may have been undetected due to poor sequencing coverage.

518 Second, the limited number of viruses identified is likely to reflect the high levels of

519 sequence divergence expected for protist viruses compared to those currently available in

520 sequence databases. Indeed, many of the viruses identified in this study share less than 30-

$52140 \%$ sequence identity, toward what might be the limit of a viable BLAST-based analysis.

522 Hence, this study has been conducted at the boundaries of the detectable virosphere, with a

523 myriad of more divergent viruses yet to be discovered.

\subsection{RNA virus are widespread among lineages of unicellular algae}

526 Our knowledge of RNA viruses associated with microalgae is scarce. The small number reported so far are mostly associated with a specific subset of algal species from the Bacillariophyta and Chlorophyta, ignoring the wide diversity of microalgae (Figure 1A). We extend this diversity by revealing, for the first time, RNA viruses (i.e. RdRp sequences) in the Haptophyta, Chromeraceae (Alveolates), as well as in the Stramenopiles Xanthophyceae and Bolidophyceae. We also identified new virus-algae clade associations. For example, we present the first observation of Picornavirales, Ghabrivirales (Totiviridae) and Durnavirales (Partititivridae) in Dinophyceae cultures, Lenarviricota and Durnavirales in Rhodophyta cultures, and Durnavirales in Bacillariophyta cultures. Importantly, our study also constitutes 
the first observation of a Muvirales-like ssRNA- virus in a Bacillariophyta sample, perhaps only the second negative-sense RNA virus identified in microalgae. reported $^{39,40}$, all the viruses described in this study represent the first observation of an RNA virus in each respective host species. In addition, none of the 73 microalgal viruses reported previously were identified here. More generally, the distribution of RNA viruses obtained in this study, comprising ssRNA+, ssRNA- and dsRNA viruses, varies considerably between taxa and likely reflects sampling bias rather than a host specificity of RNA virus infection.

These factors might have contributed to the lack of viral identification in poorly investigated and divergent taxa such as Euglena, Glaucophytes and Cryptophytes. Further studies with particular emphasis on these taxa are clearly required.

Chloroarachniophyte $C$. reptans (Cercozoa) and bunya-like siRNAs in brown algae viruses. Interestingly, the related Qinviridae and Yueviridae have been exclusively identified from meta-transcriptomic studies conducted on marine arthropods holobionts, such that algae could constitute the true hosts for most of these viruses ${ }^{42,43}$. Undoubtedly, the presence of ssRNA- viruses in microbial eukaryotes needs to be further characterized.

\subsection{Narnaviridae-like and Mitoviridae-like viruses are common in microalgal cultures}

A third of the viruses reported here were from the order Lenarviricota that includes the 
recently been associated with a wide range of protist organisms, including protozoan parasites like Plasmodium vivax ${ }^{45-48}$ and the oomycete Phytophthora infestans ${ }^{49}$, while narnalike viruses have also been detected in diatoms ${ }^{50}$. Similarly, the Mitoviridae were considered as exclusively infecting fungi, until the recent discovery of the Chenopodium quinoa mitovirus 1 in a plant ${ }^{51}$ and mito-like viruses in the Chlorophyta Osteobium sp..$^{52}$ led their host range to be re-evaluated. The three new narna-like viruses in Bacillariophyta discovered here, as well as the proposal of seven new mitovirus-like species in algal lineages as diverse as Haptophyta, Bacillariophyta, Rhodophyta and Chlorophyta, provides further evidence for the ubiquity of these viruses in protists.

Whether all the mitoviruses documented here are associated with the mitochondria, as typical of the Mitoviridae, remains to be determined. In addition, while the unique RdRpencoding segment has already been demonstrated as sufficient for virus infectivity, recent studies have suggested the presence of an additional segment, without an assigned function, in both Leptomonas seymouri and Plasmodium vivax ${ }^{45,48}$. Whether the viruses newly described here have unsegmented or bipartite genomes remains to be determined. Most of the Lenarviricota-like sequences described here display ambigrammatic ORFs, with their reverse strand encoding additional ORFs. This feature has already been reported in narnaviruses and could represent a potential solution to extreme genome compaction ${ }^{53-55}$.

The growing evidence for the extended host range of both Narnaviridae and Mitoviridae beyond the fungal clades has important consequences in our knowledge of the early events in the evolution of eukaryotic RNA viruses. Indeed, the ubiquity of Mitoviridae and Narnaviridae in eukaryotes is compatible with the protoeukaryotic origins of these viruses and the bacterial Leviviridae, such that they are relics of a past endosymbiont infection of a eukaryotic ancestor. Accordingly, cytoplasmic Narnaviridae would have escaped from mitochondria to the more RNA hospitable $\mathrm{cytosol}^{3}$. In addition, Narnaviridae 
and Mitoviridae are not associated with cellular membranes ${ }^{56}$, which could also reflect their ancient origin from a protoeukaryote ancestor without cellular compartments.

\subsection{The extension of the Marnaviridae to new algal taxa}

Most of the algal RNA viruses described to date belong to the order Picornavirales, including the Marnaviridae. Currently, the Marnaviridae comprise 20 species, distributed among seven genera based on their capsid similarities. Notably, all these viral species are associated with marine samples or algae cultures ${ }^{57}$. The three picorna-like viruses newly identified in this study fell within the Marnaviridae. Despite similar genome organizations, these three viruses have relatively high levels of divergence from known Marnaviridae, in turn suggesting that the Marnaviridae diversity has only been sparsely sampled. This diversity will very likely increase with the sequencing of phytoplankton cells. While the detection of Neleus marna-like virus and Tyro marna-like virus in Bacillariophyta and Xanthophyceae could reflect the specificity of Sogarnavirus and Kusarnavirus to Stramenopile algae, the first detection of a Marnaviridae-like virus in the Dinophyceae species Symbiodinium sp. suggests that the host range of this algal-infecting viral family is not restricted to Stramenopile eukaryotes.

\subsection{The ancestry of the Durnavirales and Ghabrivirales dsRNA viruses}

604 Approximately half of the RNA viruses identified in this study are related to the Totiviridae 605 (Ghabrivirales) and Partitiviridae (Durnavirales) families of dsRNA virus. The Totiviridae currently comprises 28 formally-assigned species divided into five genera ${ }^{32,58}$. Interestingly,

607 Totiviridae are exclusively associated with unicellular eukaryotes, with two of the five 
Trichomonasvirus, Giardiavirus and Leishmaniavirus have been associated with protozoan parasite infections ${ }^{32}$. previously reported in Bacillariophyta diatoms ${ }^{59,60}$ and the Rhodophyta Delisea pulchra ${ }^{61}$. clade in the genus Totivirus that will need to be confirmed with studies of additional species.

619 It was also notable that other toti-like viruses identified here cluster with viruses found in non-algal hosts, such as invertebrates (ticks, crustaceans), fungi and protozoan parasites. While host mis-annotations cannot be formally excluded, the presence of Totiviridae in protozoan parasites, fungi and algae could signify that the host range of the Totiviridae is far larger than appreciated.

Six dsRNA-like new viruses identified here show clear homology with those of the order Durnavirales, including the Partitiviridae and the Amalgaviridae that comprise bisegmented and unsegmented dsRNA viruses, respectively. The Partitiviridae are classified into five genera and mainly associated with plants and fungi, although more recently with oomycetes $^{62}$ and to Apicomplexa ${ }^{63}$. The Amalgaviridae comprise two genera associated with either fungi (Zybavirus genus) or land plants (Amalgavirus genus) ${ }^{58,64}$. In addition to the recent association of newly described partiti- and amalgavirus-like viruses in the microalgae Ostreobium sp. (Cholorophyta) $)^{52}$, our identification of these novel and divergent viral order has been underestimated. 


\subsection{Are cryptic viruses a common feature of unicellular eukaryotes?}

RNA viruses causing host cell lysis and hence mortality are commonly reported ${ }^{65}$, with an

emblematic example being the lysis of the harmful algal bloom-forming diatoms, haptophytes and dinoflagellates, leading to bloom collapse ${ }^{66,67}$. Although we did not aim to assess the phenotypic effects of viral infection on algal hosts, it is noticeable that most of the viruses identified here were related to the Totiviridae, Partitiviridae, Mitoviridae and Narnaviridae, all previously reported as associated with cryptic and persistent infections ${ }^{32}$. This is consistent with the design of the MMETSP study that would tend to identify non-pathogenic viruses. It is also in accordance with the growing evidence that a non-neglectable component of RNA virus-host associations are symptomless or even beneficial to their host, with potentially importations evolutionary implications ${ }^{68,69}$.

\subsection{Limitations to virus discovery and inferring virus-host relationships}

A key element of this study was use of mono-strain cultures, which were axenic whenever possible, enabling more accurate virus-host assignments. While Bacteria, and to a lesser extent, Archaea, were present in the non-axenic cultures, the placement of most of the newly described viruses within eukaryotic-infecting viral families clearly supports their association with algae. Despite this, some of the newly- described viruses were associated with viral lineages traditionally associated with fungal or metazoan hosts. This likely reflects the lack of representation of microalgal viruses in current sequence databases or a mis-annotation to secondary metazoan host, particularly given the recent efforts to describe the fungal virome $^{70-73}$. Similarly, many of the newly identified viruses share homology with viruses identified in metagenomics studies on marine invertebrates ${ }^{36}$. It is widely established that such similarities to holobiont virome studies should be treated with caution, as the viruses 
reported could in fact be infecting symbionts, eukaryotic parasites, or bacteria that are also

661 present in these samples ${ }^{3}$. Marine invertebrate organisms are also important ocean filters and virus removers ${ }^{74}$, again compatible with the idea that at least some of the viruses identified here may infect other marine organisms.

We also attempted to identify more distant RNA viruses using a protein profile and structural-based approach. However, no remote RNA virus signals could be confidently detected using this method, although a distant endogenous viral element in Bigelowiella was identified. While the de novo prediction of protein 3D structures has experienced major improvements over the last decade ${ }^{75}$, revealing robust homology strongly relies on structural comparisons and modelling based on pre-existing structures ${ }^{22}$. Critically, however, only a very limited number of non-human viruses are available among the viral proteins deposited in the Protein Data Bank. This poor representativeness of protein structures is a major roadblock in the ability to detect highly divergent RdRps. Indeed, a better characterization of RdRp structures combined with the enrichment of RdRp motif and profile databases will help counter the challenge posed by the high levels of sequence divergence in protist samples and the concomitant loss of detectable evolutionary signals. In addition, the high percentage of false positives in the HMM analysis highlights the need to increase and optimize the sensitivity and stringency of such methods.

While our study significantly extends our knowledge of RNA virus diversity among unicellular eukaryotes, experimental confirmation is needed to formally assign such viruses to their specific microalgae hosts and to assess the impact of viral infection on host biology. Perhaps more importantly, additional effort is needed to detect the signal of remote sequence homology in the highly divergent RNA viruses that are likely commonplace in protists.

\section{Acknowledgments}


684 SM thanks the Moore Foundation for funding her involvement in the MMETSP project. ECH

685 is funded by an Australian Research Council Australian Laureate Fellowship (FL170100022).

686

687 Data availability

688 All viral genomes and corresponding sequences detected in this study will be deposited in the

689 NCBI GenBank and SRA upon the acceptance. The accessions ID will be listed in Table 1. 
690

691

692

\section{References}

1. Wigington CH, Sonderegger D, Brussaard CPD, Buchan A, Finke JF, Fuhrman JA et al. Re-examination of the relationship between marine virus and microbial cell abundances. Nat Microbiol 2016; 1: 15024.

2. Suttle CA. Marine viruses-major players in the global ecosystem. Nat Rev Microbiol 2007; 5: 801-812.

3. Dolja V V., Koonin E V. Metagenomics reshapes the concepts of RNA virus evolution by revealing extensive horizontal virus transfer. Virus Res 2018; 244: 36-52.

4. Burki F, Roger AJ, Brown MW, Simpson AGB. The new tree of eukaryotes. Trends Ecol Evol 2020; 35: 43-55.

5. Pawlowski J, Audic S, Adl S, Bass D, Belbahri L, Berney C et al. CBOL protist working group: barcoding eukaryotic richness beyond the animal, plant, and fungal kingdoms. PLoS Biol 2012; 10: e1001419.

6. Raoult D, Forterre P. Redefining viruses : lessons from Mimivirus. Nat Rev Microbiol $2008 ; 6:$ 315-319.

7. Tai V, Lawrence JE, Lang AS, Chan AM, Culley AI, Suttle CA. Characterization of Harnav, a single-stranded RNA virus causing lysis of Heterosigma akashiwo (Raphidophyceae). J Phycol 2003; 39: 343-352.

8. Short SM, Staniewski MA, Chaban Y V, Long AM, Wang D. Diversity of viruses infecting eukaryotic algae. Curr Issues Mol Biol 2020; 39: 29-62.

9. Brum JR, Cesar Ignacio-Espinoza J, Roux S, Doulcier G, Acinas SG, Alberti A et al. Patterns and ecological drivers of ocean viral communities. Science 2015; 348: 25.

10. Gregory AC, Zayed AA, Conceição-Neto N, Temperton B, Bolduc B, Alberti A et al. Marine DNA viral macro- and microdiversity from pole to pole. Cell 2019; 177: 11091123. 
11. Steward GF, Culley AI, Mueller JA, Wood-Charlson EM, Belcaid M, Poisson G. Are we missing half of the viruses in the ocean? ISME J 2013; 7: 672-679.

12. Wolf YI, Silas S, Wang Y, Wu S, Bocek M, Kazlauskas D et al. Doubling of the known set of RNA viruses by metagenomic analysis of an aquatic virome. Nat Microbiol 2020; 5: $1-9$.

13. Simmonds P, Adams MJ, Benkő M, Breitbart M, Brister JR, Carstens EB et al. Virus taxonomy in the age of metagenomics. Nat Rev Microbiol 2017; 15: 161-168.

14. Nissimov JI, Campbell CN, Probert I, Wilson WH. Aquatic virus culture collection: an absent (but necessary) safety net for environmental microbiologists. Appl Phycol 2020; doi: $10.1080 / 26388081.2020 .1770123$

15. Keeling PJ, Burki F, Wilcox HM, Allam B, Allen EE, Amaral-Zettler LA et al. The marine microbial eukaryote transcriptome sequencing project (MMETSP): illuminating the functional diversity of eukaryotic life in the oceans through transcriptome sequencing. PLoS Biol 2014; 12: e1001889.

16. Johnson LK, Alexander H, Brown CT. Re-assembly, quality evaluation, and annotation of 678 microbial eukaryotic reference transcriptomes. Gigascience 2019; 8: 1-12.

17. Swart EC, Serra V, Petroni G, Nowacki M. Genetic codes with no dedicated stop codon: context-dependent translation termination. Cell 2016; 166: 691-702.

18. Buchfink B, Xie C, Huson DH. Fast and sensitive protein alignment using DIAMOND. Nat Methods 2015; 12: 59-60.

19. Giangaspero M. Pestivirus species potential adventitious contaminants of biological products. Trop Med Surg 2013; 1:1000153.

20. El-Gebali S, Mistry J, Bateman A, Eddy SR, Luciani A, Potter SC et al. The Pfam protein families database in 2019. Nucleic Acids Res 2019; 47: D427-D432.

21. Eddy SR. Accelerated profile HMM searches. PLoS Comput Biol 2011; 7: e1002195. 
22. Kelley LA, Mezulis S, Yates CM, Wass MN, Sternberg MJE. The Phyre2 web portal for protein modeling, prediction and analysis. Nat Protoc 2015; 10: 845-858.

23. Venkataraman S, Prasad BVLS, Selvarajan R. RNA Dependent RNA polymerases: insights from structure, function and evolution. Viruses 2018; 10: 76.

24. Kearse M, Moir R, Wilson A, Stones-Havas S, Cheung M, Sturrock S et al. Geneious Basic: An integrated and extendable desktop software platform for the organization and analysis of sequence data. Bioinformatics 2012; 28: 1647-1649.

25. Langmead B, Salzberg SL. Fast gapped-read alignment with Bowtie 2. Nat Meth 2012; 9: $357-359$.

26. Pettersson JH-O, Ellström P, Ling J, Nilsson I, Bergström S, González-Acuña D et al. Circumpolar diversification of the Ixodes uriae tick virome. PLOS Pathog 2020; 16: e1008759.

27. Katoh K, Standley DM. MAFFT multiple sequence alignment software version 7: improvements in performance and usability. Mol Biol Evol 2013; 30: 772-780.

28. Nguyen L-T, Schmidt HA, von Haeseler A, Minh BQ. IQ-TREE: A fast and effective stochastic algorithm for estimating maximum-likelihood phylogenies. Mol Biol Evol $2015 ; 32: 268-274$.

29. Kalyaanamoorthy S, Minh BQ, Wong TKF, von Haeseler A, Jermiin LS. ModelFinder: fast model selection for accurate phylogenetic estimates. Nat Methods 2017; 14: 587 589.

30. Minh BQ, Nguyen MAT, Von Haeseler A. Ultrafast approximation for phylogenetic bootstrap. Mol Biol Evol 2013; 30: 1188-1195.

31. Mihara T, Nishimura Y, Shimizu Y, Nishiyama H, Yoshikawa G, Uehara H et al. Linking virus genomes with host taxonomy. Viruses 2016; 8: 66.

32. Lefkowitz EJ, Dempsey DM, Hendrickson RC, Orton RJ, Siddell SG, Smith DB. Virus 
taxonomy: the database of the International Committee on Taxonomy of Viruses (ICTV). Nucleic Acids Res 2018; 46: D708-D717.

33. John DE, Patterson SS, Paul JH. Phytoplankton-group specific quantitative polymerase chain reaction assays for RuBisCO mRNA transcripts in seawater. Mar Biotechnol 2007;

$$
\text { 9: } 747-759 \text {. }
$$

34. Bolch CJS, Subramanian TA, Green DH. The toxic dinoflagellate gymnodinium catenatum (Dinophyceae) Requires marine bacteria for growth. J Phycol 2011; 47: 10091022.

35. Wolf YI, Kazlauskas D, Iranzo J, Lucía-Sanz A, Kuhn JH, Krupovic M et al. Origins and evolution of the global RNA virome. MBio 2018; 9: e02329-18.

36. Shi M, Lin X-D, Tian J-H, Chen L-J, Chen X, Li C-X et al. Redefining the invertebrate RNA virosphere. Nature 2016; 540: 539-543.

37. Shi M, Lin X-D, Chen X, Tian J-H, Chen L-J, Li K et al. The evolutionary history of vertebrate RNA viruses. Nature 2018; 556: 197-202.

38. Geoghegan JL, Di Giallonardo F, Cousins K, Shi M, Williamson JE, Holmes EC. Hidden diversity and evolution of viruses in market fish. Virus Evol 2018; 4: vey031.

39. Correa AMS, Welsh RM, Vega Thurber RL. Unique nucleocytoplasmic dsDNA and ${ }_{+}$ssRNA viruses are associated with the dinoflagellate endosymbionts of corals. ISME J $2013 ; 7: 13-27$.

40. Levin RA, Voolstra CR, Weynberg KD, Van Oppen MJH. Evidence for a role of viruses in the thermal sensitivity of coral photosymbionts. ISME J 2017; 11: 808-812.

41. Waldron FM, Stone GN, Obbard DJ. Metagenomic sequencing suggests a diversity of RNA interference-like responses to viruses across multicellular eukaryotes. PLoS Genet 2018; 14: e1007533.

42. Käfer S, Paraskevopoulou S, Zirkel F, Wieseke N, Donath A, Petersen M et al. Re- 
assessing the diversity of negative strand RNA viruses in insects. PLoS Pathog 2019; 15: e1008224.

43. Wu H, Pang R, Cheng T, Xue L, Zeng H, Lei T et al. Abundant and diverse RNA viruses in insects revealed by RNA-Seq analysis: ecological and evolutionary implications. mSystems 2020; 5 :e00039-20

44. Hillman BI, Cai G. The family Narnaviridae: simplest of RNA viruses. Adv Virus Res 2013; 86: 149-176.

45. Lye L-F, Akopyants NS, Dobson DE, Beverley SM. A narnavirus-like element from the trypanosomatid protozoan parasite Leptomonas seymouri. Genome Announc 2016; 4: $713-729$.

46. Grybchuk D, Kostygov AY, Macedo DH, d'Avila-Levy CM, Yurchenko V. RNA viruses in trypanosomatid parasites: a historical overview. Mem Inst Oswaldo Cruz 2018; 113: e170487.

47. Akopyants NS, Lye L-F, Dobson DE, Lukeš J, Beverley SM. A narnavirus in the trypanosomatid protist plant pathogen Phytomonas serpens. Genome Announc 2016; 4: e00711-16.

48. Charon J, Grigg MJ, Eden JS, Piera KA, Rana H, William T et al. Novel RNA viruses associated with Plasmodium vivax in human malaria and Leucocytozoon parasites in avian disease. PLoS Pathog 2019; 15: e1008216.

49. Cai G, Myers K, Fry WE, Hillman BI. A member of the virus family Narnaviridae from the plant pathogenic oomycete Phytophthora infestans. Arch Virol 2012; 157: 165-169.

50. Urayama SI, Takaki Y, Nunoura T. FLDS: A comprehensive DSRNA sequencing method for intracellular RNA virus surveillance. Microbes Environ 2016; 31: 33-40.

51. Nerva L, Vigani G, Di Silvestre D, Ciuffo M, Forgia M, Chitarra W et al. Biological and molecular characterization of Chenopodium quinoa Mitovirus 1 reveals a distinct small 
RNA response compared to those of cytoplasmic RNA viruses. J Virol 2019; 93: e01998-18.

52. Charon J, Marcelino VR, Wetherbee R, Verbruggen H, Holmes EC. Metatranscriptomic identification of diverse and divergent RNA viruses in green and chlorarachniophyte algae cultures. Viruses 2020; 12: 1180.

53 . DeRisi JL, Huber G, Kistler A, Retallack H, Wilkinson M, Yllanes D. An exploration of

54. Belshaw R, Pybus OG, Rambaut A. The evolution of genome compression and genomic novelty in RNA viruses. Genome Res 2007; 17: 1496-1504.

55. Dinan AM, Lukhovitskaya NI, Olendraite I, Firth AE. A case for a negative-strand coding sequence in a group of positive-sense RNA viruses. Virus Evol 2020; 6: veaa007.

56. Solórzano A, Rodríguez-Cousiño N, Esteban R, Fujimura T. Persistent yeast single-

57. Vlok M, Lang AS, Suttle CA. Application of a sequence-based taxonomic classification method to uncultured and unclassified marine single-stranded RNA viruses in the order Picornavirales. Virus Evol 2019; 5: vez056.

58. Walker PJ, Siddell SG, Lefkowitz EJ, Mushegian AR, Adriaenssens EM, Dempsey DM et al. Changes to virus taxonomy and the statutes ratified by the International Committee genomes identified from marine macroalgae and a diatom. Microbes Environ 2020; 35: ME20016. segmented double-stranded RNA virus from an Arctic isolate of Pythium polare. 
61. Lachnit T, Thomas T, Steinberg P. Expanding our understanding of the seaweed holobiont: RNA viruses of the red alga Delisea pulchra. Front Microbiol 2016; 6: 1489.

62. Shiba K, Hatta C, Sasai S, Tojo M, T. Ohki S, Mochizuki T. Genome sequence of a novel partitivirus identified from the oomycete Pythium nunn. Arch Virol 2018; 163:

63. Nibert ML, Woods KM, Upton SJ, Ghabrial SA. Cryspovirus: a new genus of protozoan viruses in the family Partitiviridae. Arch Virol 2009; 154: 1959-1965.

65. Middelboe M, Brussaard C. Marine viruses: key players in marine ecosystems. Viruses 2017; 9: 302.

66. Nagasaki K. Dinoflagellates, diatoms, and their viruses. J Microbiol 2008; 46: 235-243.

67. Brussaard CPD, Martínez J. Algal bloom viruses. Plant Viruses 2008; 2: 1-10.

68. Takahashi H, Fukuhara T, Kitazawa H, Kormelink R. Virus latency and the impact on plants. Front Microbiol 2019; 10: 2764.

69. Roossinck MJ. The good viruses: Viral mutualistic symbioses. Nat Rev Microbiol 2011;

$$
\text { 9: 99-108. }
$$

70. Deakin G, Dobbs E, Bennett JM, Jones IM, Grogan HM, Burton KS. Multiple viral infections in Agaricus bisporus - Characterisation of 18 unique RNA viruses and 8 ORFans identified by deep sequencing. Sci Rep 2017; 7: 1-13.

71. Ghabrial SA, Castón JR, Jiang D, Nibert ML, Suzuki N. 50-plus years of fungal viruses. Virology 2015; 479-480: 356-368.

72. Marzano S-YL, Nelson BD, Ajayi-Oyetunde O, Bradley CA, Hughes TJ, Hartman GL et 
al. Identification of diverse mycoviruses through metatranscriptomics characterization of

866 the viromes of five major fungal plant pathogens. J Virol 2016; 90: 6846-6863.

867 73. Xie J, Jiang D. New insights into mycoviruses and exploration for the biological control 868 of crop fungal diseases. Annu Rev Phytopathol 2014; 52: 45-68.

869 74. Welsh JE, Steenhuis P, de Moraes KR, van der Meer J, Thieltges DW, Brussaard CPD. Marine virus predation by non-host organisms. Sci Rep 2020; 10: 1-9.

871 75. Callaway E. 'It will change everything': DeepMind's AI makes gigantic leap in solving protein structures. Nature 2020; 588: 203-204. 